\title{
La LIEN y los educadores españoles: una historia de desencuentros e infidelidades
}

\author{
(Spanish educators and the New Education Fellowship: a history of \\ disagreement and disloyalty)
}

\author{
María del Mar DEL POZO ANDRÉS \\ Universidad de Alcalá
}

RESUMEN: El artículo trata de responder a la siguiente pregunta: ¿Por qué el movimiento español de Escuela Nueva fue invisible en los espacios de encuentro internacionales de los años veinte y treinta? Para ello se ha utilizado una metodología basada en la perspectiva teórica y metodológica del análisis de networks o redes de relaciones. Se analizan las relaciones de los educadores españoles con la Ligue International d'Éducation Nouvelle/New Education Fellowship, a través de su presencia en espacios de encuentro como los congresos internacionales y las revistas Pour l'Ëre Nouvelle y The New Era. El estudio abarca los años 1921-1936 y se divide en tres etapas, marcadas por la evolución de la Sección Española de la Liga y de su órgano de expresión, la Revista de Pedagogía. Se concluye con tres posibles razones que explican la invisibilidad internacional del movimiento español de Escuela Nueva: la desunión de los educadores de los grupos implicados; la visión pobre e instrumental que se crearon los representantes europeos de la realidad educativa española y la incapacidad de los educadores españoles para construir y transmitir un relato propio sobre el movimiento de la Escuela Nueva en nuestro país.

PALABRAS CLAVE: Escuela Nueva, España, redes de relaciones, Liga Internacional de Educación Nueva

ABSTRACT: The article attempts to account for the relative invisibility of the Spanish New Education movement in international pedagogy in the 1920s and 1930s. Using network theory and methods, the analysis explores the relationship of Spanish educators with the New Education Fellowship through their participation in pedagogical spaces such as international conferences and the magazines Pour l'Erre Nouvelle and The New Era. The study covers the years 19211936 and is divided into three periods, based on the evolution of the Spanish Section of the Fellowship and its official organ, the Revista de Pedagogía. The analysis identifies three possible reasons for the scant international presence of the Spanish New Education movement: the disunity of the educators and groups involved; the limited, instrumental view of Spanish education self-created by the European representatives; and the inability of Spanish educators to construct and transmit their own narrative of the New School movement in Spain.

KEY WORDS: progressive education; Spain; networks; New Education Fellowship 


\section{Introducción: ¿Pero hubo alguna vez un movimiento de Escuela Nueva en España?}

La pregunta que da título a este epígrafe fue una de las primeras que me planteé cuando empecé a hacer mis primeros acercamientos como historiadora de la educación. Los libros dedicados al movimiento de la Escuela Nueva, que ya eran obras de carácter histórico, citaban muy numerosas experiencias, métodos, instituciones y reformas acontecidas en todas partes del mundo, pero a España nunca se la mencionaba. Recuerdo mi emoción cuando encontré un pequeño epígrafe en un manual de Luzuriaga dedicado a "Las escuelas nuevas españolas", en el que situaba a la ILE como escuela nueva, "precursora en muchos aspectos de las posteriores de Europa" y mencionaba tres escuelas públicas "que disfrutaron de autonomía para realizar sus experiencias pedagógicas y que fueron verdaderas escuelas nuevas", el Grupo escolar Cervantes, el Instituto-Escuela en Madrid y el Grupo escolar Baixeras de Barcelona. ${ }^{1}$ En mi tesina, escrita en 1981 y dedicada al primero de los tres centros mencionados, intenté demostrar que éste cumplía con al menos quince de los treinta principios de la Nueva Educación formulados en 1919 y publicados por primera vez en 1925, que era el criterio establecido por el propio Ferrière para acreditar la pertenencia de una escuela al movimiento. ${ }^{2}$

Algunas investigaciones de las últimas décadas del siglo XX permitieron desvelar muchos aspectos inexplorados sobre la presencia e influencia de la Escuela Nueva en España: su recepción a través de los cientos de traducciones y de artículos en revistas; la observación casi en tiempo real de las experiencias prácticas extranjeras que pudieron realizar muchos docentes gracias a las ayudas económicas de la Junta para Ampliación de Estudios y otras instituciones provinciales y locales; el papel que la Escuela Superior del Magisterio cumplió como catalizador del movimiento; y la rápida difusión que se hizo de las nuevas ideas y métodos a través de los cursos de perfeccionamiento, de las Escuelas Normales y de las obras de pedagogos españoles que divulgaron y vulgarizaron las ideas y los métodos de la Escuela Nueva. Cuando la historiografía empezó a adoptar enfoques culturales y a analizar las prácticas en el aula, se pudo comprobar que las innovaciones educativas de origen escolanovista eran aplicadas en muchas escuelas, si bien adaptadas y mediatizadas por la cultura escolar previa de cada docente. Las aportaciones historiográficas de las primeras décadas del siglo XXI, que manejan fuentes diferentes como las imágenes, los cuadernos de clase, los egodocumentos, los diarios y los archivos de maestros, han permitido descubrir la coreografía de la renovación escolar, es decir, las estructuras y movimientos que se producían en una escuela para convertirla en "nueva". El análisis de las decenas de experiencias educativas que se publicaron entre 1922 y 1936 nos ayudó a comprender los modos en los que las prácticas innovadoras se imbricaban con las tradicionales, dando lugar a híbridos didácticos difícilmente categorizables como "antiguos" 0 "nuevos". ${ }^{3}$

\footnotetext{
${ }^{1}$ Lorenzo Luzuriaga, Historia de la Educación y de la Pedagogía (Buenos Aires: Losada, 19656), 233-234.

${ }^{2}$ María del Mar del Pozo Andrés, "Las "fundaciones" de Ángel Llorca”, en Comunidades Familiares de Educación. Un modelo de renovación pedagógica en la Guerra Civil (Barcelona: Octaedro, 2008), 72.

${ }^{3}$ María del Mar del Pozo Andrés, "La renovación pedagógica en España (1900-1939): Etapas, características y movimientos", en V Encontro Ibérico de História da Educação. Renovação Pedagógica, ed. Ernesto Candeias
} 
Un balance rápido de la producción historiográfica generada en estos últimos cuarenta años nos permite constatar que en España existió un amplio movimiento de renovación pedagógica en el primer tercio del siglo XX y que ese movimiento tuvo un gran paralelismo en cuanto a ideas, modelos, prácticas y tiempos, con el desarrollo de la Escuela Nueva a nivel mundial. Por eso sorprende su invisibilidad en los espacios pedagógicos internacionales. En un artículo anterior, que terminé con la misma pregunta con la que he iniciado éste, avancé algunas razones de esta invisibilidad, justificadas desde el comportamiento colectivo de los innovadores españoles, que se caracterizó por "el individualismo, la ausencia de líneas comunes, la imposibilidad de trabajar cooperativamente y, sobre todo, la falta de estímulos para divulgar los resultados de sus experiencias más allá de nuestras fronteras". ${ }^{4}$ En este artículo pretendo retomar estas reflexiones que me dejé hilvanadas hace ya unos cuantos años y comprobar si la incapacidad de transmitir ante el mundo una imagen de unidad sirve para explicar el silencio generalizado que se cernió sobre el escolanovismo español. Mi objetivo es contrastar la actitud de los educadores españoles frente al movimiento de la Escuela Nueva con el comportamiento de los representantes internacionales de este movimiento frente a España. Y este estudio se va a realizar desde la perspectiva teórica y metodológica que nos ofrece el análisis de los networks o las redes de relaciones sociales.

El análisis de networks como enfoque historiográfico ha sido utilizado extensamente en la investigación histórica con la aplicación de métodos propios de las Ciencias Sociales. Independientemente de las técnicas que se utilicen, la adopción del paradigma del network implica analizar la realidad histórica desde una perspectiva relacional, es decir, pretende describir las relaciones y los lazos creados entre individuos como una forma de explicar el modo en el que determinadas innovaciones circularon entre ellos. ${ }^{5}$ En la Historia de la Ciencia se han seguido modelos más cualitativos, centrados en estudios de casos y en un nivel micro que permite mostrar en detalle cómo se construyeron los contactos y las colaboraciones científicas. ${ }^{6}$ La Historia de la Educación se acercó a este paradigma en la primera década del siglo XXI, adoptando posiciones cualitativas, prefiriendo describir los networks más que medirlos y cuantificarlos. ${ }^{7}$ Muchos de estos traba-

(Castelo Blanco: Alma Azul, 2005), 143-159.

${ }^{4}$ María del Mar del Pozo Andrés, "La Escuela Nueva en España: Crónica y semblanza de un mito", Historia de la Educación. Revista Interuniversitaria 22-23 (2003-2004): 344.

${ }^{5}$ Laurent Beauguitte, "L'analyse de réseaux en sciences sociales et en histoire: vocabulaire, principes et limites", en Le réseau. Usages d'une notion polysémique en sciences humaines et sociales, eds. Rosemonde Latricot al., (Louvain: UCL Presses Universitaires de Louvain, 2016), 9-24 y Claire Lemercier, "Formal network methods in history: why and how?", en Social Networks, Political Institutions, and Rural Societies, ed. Georg Fertig (Turnhout: Brepols Publishers, 2015), 281-310.

${ }^{6}$ Abraham S.H. Breure y Raphael H. Heiberger, "Reconstructing science networks from the past. Eponyms between malacological authors in the mid-19 $9^{\text {th }}$ century", Journal of Historical Network Research 3 (2019): 92-117.

${ }^{7}$ Eckhardt Fuchs, "Networks and the History of Education", Paedagogica Historica XLIII, no. 2 (2007): 191. Algunos de los enfoques y tendencias utilizados en la investigación histórico-educativa fueron presentados en la colección de artículos que compone ese monográfico, que constituye un buen ejemplo de análisis de casos históricos de networks formales e informales, nacionales e internacionales. Eckhardt Fuchs, Daniel Lindmark, 
jos pioneros mostraron cómo la I Guerra Mundial interrumpió abruptamente la mayoría de las relaciones internacionales establecidas en el mundo de la educación a través de congresos, exposiciones universales y organizaciones internacionales. La creación de la Liga de Naciones en 1919 impulsó enormemente la aparición de nuevas organizaciones transnacionales, una de las cuales fue la denominada en los países anglosajones New Education Fellowship (NEF), y en los países latinos Ligue Internationale pour l'Éducation Nouvelle (LIEN).

La bibliografía sobre networks pedagógicos publicada en las dos últimas décadas se ha centrado, precisamente, en estudiar cómo las redes de relaciones creadas entre los representantes del movimiento de la Escuela Nueva sirvieron para potenciar, publicitar y elevar al estrellato a determinadas figuras, ideas y métodos integrados en el movimiento. Se ha ido comprobando que el éxito o el fracaso de los proyectos educativos innovadores se debió, no tanto a la novedad intrínseca de las propuestas, sino a la forma en la que fueron presentadas y "vendidas" en el mercado pedagógico. Podemos hablar de la existencia de una tradición historiográfica sobre las redes pedagógicas en el movimiento de la Escuela Nueva iniciada por Peter Cunningham, quien señaló la necesidad de estudiar a los innovadores en el contexto de los networks y estructuras cruzadas a través de los cuales operaron. ${ }^{8}$ En esta misma línea se sitúan los trabajos de Van Gorp, Depaepe y Simon sobre los congresos y las sociedades científicas como medio de difusión y comunicación del conocimiento en torno al educador Ovide Decroly; ${ }^{9}$ el de Sylvain Wagnon sobre las redes de relaciones científicas del doctor belga a partir de su correspondencia; ${ }^{10}$ los de Peter Cunningham, Gutek \& Gutek y Pozo \& Braster sobre el papel que cumplió el networking transnacional en la rápida expansión del sistema Montessori y del Plan Dalton; ${ }^{11}$ los de Richard Aldrich, Martin Lawn y Rita Hofstetter sobre los institutos de investigación

\footnotetext{
y Christoph Lüth, eds., "Networks and the History of Education", Paedagogica Historica 43, no. 2 (2007): 185294. Otros casos que muestran los networks creados en espacios marcados por grandes distancias geográficas fueron recogidos en Gary McCulloch y Roy Lowe, eds., "Centre and periphery - networks, space and geography in the history of education", History of Education 32, no. 5 (2003): 457-594.

${ }^{8}$ Peter Cunningham, "Innovators, networks and structures: towards a prosopography of progressivism", History of Education 30, no. 5 (2001): 433-451.

${ }^{9}$ Angelo van Gorp, Marc Depaepe y Frank Simon, "Backing the actor as agent in discipline formation: an example of the "secondary disciplinarization" of the educational sciences, based on the networks of Ovide Decroly (1901-1931)", Paedagogica Historica 40, nos. 5-6 (2004): 591-616 y Angelo van Gorp, Frank Simon y Marc Depaepe, "Frictions and fractions in the new education fellowship, 1920s-1930s: Montessori(ans) vs. Decroly(ans)", History of Education \& Children's Literature XI, no. 1 (2017): 251-270.

${ }^{10}$ Sylvain Wagnon, "La correspondance d'Ovide Decroly (1871-1932): reflet d'une "internationale" de la psychologie européenne dans la première moitié du XXe siècle?", Recherches \& Éducations 9 (2013): 131-151. ${ }^{11}$ Peter Cunningham, "The Montessori Phenomenon: Gender and Internationalism in Early Twentieth-Century Innovation", en Practical Visionaries: Women, Education and Social Progress, 1790-1930, eds. Mary Hilton y Pam Hirsch (London: Longman, 2000), 203-220; Gerald L. Gutek y Patricia A. Gutek, Bringing Montessori to America. S.S. McClure, Maria Montessori and the Campaign to Publicize Montessori Education (Tuscaloosa: The University of Alabama Press, 2016) y María del Mar del Pozo Andrés y Sjaak Braster, "The power of networks in the marketing of pedagogical ideals: the Dalton Plan in Great Britain (1920-1925)", History of Education 47, no. 6 (2018): 840-864.
} 
pedagógica como networks transnacionales de propagación de las ideas educativas; ${ }^{12}$ el acercamiento prosopográfico de Marco Cicchini sobre los actores pedagógicos en Suiza y sus networks nacionales e internacionales ${ }^{13}$ y los enfoques de género sobre networks transnacionales de mujeres educadoras. ${ }^{14}$

La línea de investigación en la que convergen todos los estudios sobre el universo relacional del movimiento de la Escuela Nueva es la que estudia específicamente la génesis de sus networks y sus mecanismos de interrelación. Muchos trabajos pasados y recientes se dirigieron directamente al corazón del problema, analizando los espacios en los que se cruzaban y entrelazaban todas las trayectorias individuales: la organización LIEN/NEF, los congresos patrocinados por ésta y las tres revistas que fueron desde el primer momento el órgano de expresión del movimiento. Las publicaciones clásicas sobre la NEF ya pusieron de manifiesto el papel que otras sociedades previas jugaron como "superficies que permitieron emerger" la NEF.15 Las más recientes han destacado las disensiones y contradicciones doctrinales entre los principales representantes de la LIEN, ${ }^{16}$ 0 las relaciones de esta organización con algunas de las grandes figuras del movimiento, como Maria Montessori o Peter Petersen. ${ }^{17}$ También se han estudiado sus conexiones con otros organismos, como la UNESCO, después de la Segunda Guerra Mundial. ${ }^{18}$ Aún queda

\footnotetext{
${ }^{12}$ Richard Aldrich, The Institute of Education, 1902-2002. A centenary history (London: Institute of Education, 2002); Richard Aldrich, "The New Education and the Institute of Education, University of London, 1919 - 1945", Paedagogica Historica 45, nos. 4-5 (2009): 485-502; Martin Lawn, "The institute as network: the Scottish Council for Research in Education as a local and international phenomenon in the 1930s", Paedagogica Historica 40, nos. 5-6 (2004): 719-732; y Rita Hofstetter, Genève: creuset des sciences de l'éducation (fin du XIXe siècle - première moitié du XXe siècle) (Paris: Librairie Droz, 2010).

${ }^{13}$ Marco Cicchini, "Acteurs et réseaux des sciences de l'éducation: du local à l'international", en Emergence des sciences de l'éducation en Suisse, à la croisée de traditions académiques contrastées. Fin du $19^{e}$ - première moitié du 20 siècle, eds. Rita Hofstetter, Bernard Schneuwly al. (Berne: Peter Lang, 2007), 345-374.

${ }^{14}$ Tanya Fitzgerald y Elizabeth M. Smith, eds., Women Educators, Leaders and Activists: Educational Lives and Networks, 1900-1960 (Houndmills, UK: Palgrave Macmillan, 2014).

${ }^{15}$ Rabinda Sinha, "A Critical History and Evaluation of the NEF from its Foundation in 1920" (MA, Universidad de Sheffield, 1971), 161; M.D. Lawson, "The New Education Fellowship: The formative years", Journal of Educational Administration and History 13, no 2 (1981): 24-28; Celia M. Jenkins, "The professional middle class and the social origins of progressivism: A case study of the New Education Fellowship, 1920-1950" (Tesis doctoral, Instituto de Educación, Universidad de Londres, 1989), 46-48 y 72; Celia M. Jenkins, "New Education and its Emancipatory Interests (1920-1950)", History of Education 29, no. 2 (2000): 139-151 y Margaret H. White, "The New Education Fellowship: An international community of practice", New Era in Education 82, no. 3 (2001): 71-75.

${ }^{16}$ Laurent Gutierrez, "La Ligue Internationale pour l'Éducation Nouvelle. Contribution à l'histoire d'un mouvement international de réforme de l'enseignement”, Spirale. Revue de Recherches en Éducation 45 (2009): 29-42.

${ }^{17}$ Catherine L'Ecuyer, "La perspective montessorienne face au mouvement de l'éducation nouvelle dans la francophonie européenne du début du XXe siécle", European Review of History: Revue Européenne d'histoire 27, no 5 (2020): 651-682 y Hein Retter, Protestantismus und Reformpädagogik im Úbergang zur Demokratie. Studien zur Pädagogik Peter Petersens (Frankfurt: Peter Lang, 2007), 171-176.

${ }^{18}$ Christopher Clews, "The New Education Fellowship and the reconstruction of education: 1945 to 1966" (Tesis doctoral, Instituto de Educación, Universidad de Londres, 2009); Christopher Clews, "Decline and renewal: The New Education Fellowship (NEF) 1945-1955", History of Education Researcher 88 (2011): 62-71 y Joseph Watras, "The New Education Fellowship and UNESCO's programme of fundamental education", Paedagogica Historica 47, no. 1-2 (2011): 191-205.
} 
por descubrir las relaciones de la NEF/LIEN con los grupos nacionales y las tensiones específicas surgidas dentro de cada uno de ellos, si bien este enfoque se ha trabajado en algunos países. ${ }^{19}$ Desde luego, los temas más explorados son los congresos del movimiento, cuyas cambiantes orientaciones fueron estudiadas en profundidad por Kevin Brehony: ${ }^{20}$ y las revistas que se constituyeron en los órganos de expresión de la NEF/LIEN en los países anglosajones y latinos, The New Era ${ }^{21}$ y Pour l'Ere Nouvelle, ${ }^{22}$ las cuales han sido objeto de muy completos análisis en los último años.

Este artículo se sitúa en la línea de los trabajos que acabo de mencionar. La pregunta que va a acompañarme durante todo el texto es la siguiente: ¿Por qué el movimiento español de Escuela Nueva fue invisible en los espacios de encuentro internacionales de los años veinte y treinta? Voy a intentar responder a ella con explicaciones de carácter relacional, que muestren las conexiones académicas, profesionales y sociales que se establecieron entre las figuras españolas y las europeas en el espacio de comunicación de la LIEN/NEF, Para ello he explorado los que fueron sus nodos visibles de interacción: los congresos, las revistas y las reuniones de los órganos ejecutivos. Las fuentes principales de documentación han sido, en primer lugar, el archivo de la World Education Fellowship que se conserva en el Instituto de Educación de Londres, cuya información se ha complementado con la de otros archivos de pedagogos españoles y europeos ligados a la Nueva Educación; en segundo término, el análisis de contenido de las revistas más representativas del movimiento en el mundo anglosajón, latino e ibérico (The New Era,

\footnotetext{
${ }^{19}$ Patricia A. Graham, Progressive Education from Arcady to Academe: A History of the Progressive Education Association 1919-1955 (New York: Teachers College Press, 1967); Jane Abiss, "The "New Education Fellowship" in New Zealand: Its Activity and Influence in the 1930s and 1940s", New Zealand Journal of Educational Studies 33, no 1 (1998): 81-93; Laurent Gutierrez, "Les premiéres années du Groupe Français d’Éducation Nouvelle (1921-1940)", Recherches \& Éducations 4 (2011): 27-39; Sue Middleton, "Clare Soper's hat: New Education Fellowship correspondence between Bloomsbury and New Zealand (1938-1946)", History of Education 43, no. 1 (2013): 92-114; Yuko Watanabe, "'Internationalization" in the New Education Fellowship Japan Section: "Solidarité" and Kyunojo Uenuma", The Japanese Journal of Educational Research 80, no, 2 (2013): 235246 y Rafaela Rabelo y Diana Vidal, "A seçâo brasileira da new Education Fellowship: (des)encontros e (des) conexões", en Movimento internacional da educaçâo nova, eds. Diana Gonçalves Vidal y Rafaela Silva Rabelo (Belo Horizonte: Fino Traço editores, 2020), 25-47.

${ }^{20}$ Kevin J. Brehony, "A New Education for a New Era: The Contribution of the Conferences of the New Education Fellowship to the Disciplinary Field of Education 1921 - 1938", Paedagogica Historica 40, nos. 5-6 (2004): 733755 y Jean-François Condette y Antoine Savoye, "Une éducation pour une ère nouvelle, le congrès international d'éducation de Calais 1921", Études Sociales 163 (2016): 43-77.

${ }^{21}$ Steffi Koslowski, Die New Era der New Education Fellowship: Ihr Beitrag zur Internationalität der Reformpädagogik in 20. Jahrhundert (Bad Heilbrunn: Julius Klinkhardt, 2013).

${ }^{22}$ Daniel Hameline, “Les premières années de Pour l'Ėre Nouvelle: militantisme et propagande?", Les Sciences de l'éducation - Pour l'Ėre Nouvelle, 35, no. 4 (2002): 27-40; Béatrice Haenggeli-Jenni, "Pour l'Ėre Nouvelle: une revue carrefour entre science et militance (1922 - 1940)" (Tesis doctoral, Universidad de Ginebra, 2011); Béatrice Haenggeli-Jenni, “"Savoirs” constitués et programmes scolaires: débats au cœur de la revue Pour l'Ėre Nouvelle (1922-1940)", Recherches \& Éducations 4 (2011): 13-25; Béatrice Haenggeli-Jenni y Rita Hofstetter, "Pour l'Ére Nouvelle (1922 - 1940). La science convoquée pour fonder une "Internationale de l'Éducation" “", Carrefours de l'Éducation 31 (2011): 137-159 y Béatrice Haenggeli-Jenni, L'Éducation nouvelle entre science et militance. Débats et combats à travers la revue Pour l'Ėre Nouvelle (1920-1940) (Berne: Peter Lang, 2017).
} 
1920-1939; Pour l'Ėre Nouvelle, 1922-1939 y Revista de Pedagogía, 1922-1938);23 y, finalmente, una colección de informes de los congresos internacionales de la NEF/LIEN escritos por algunos de los educadores españoles asistentes a ellos. El artículo se ha sistematizado de acuerdo con criterios cronológicos, diferenciando las etapas que marcan los esfuerzos de los escolanovistas españoles para constituirse en un grupo organizado y encontrar su espacio de actuación dentro del movimiento de la Nueva Educación, y el fracaso absoluto que cosecharon en esta misión.

\section{La batalla por conseguir la representación de la LIEN en España (1921-abril de 1927)}

Los orígenes de la organización internacional de la Educación Nueva son bien conocidos. Parte del movimiento teosófico y de su entusiasmo por crear una nueva sociedad basada en individuos armónicos, espirituales y unidos por unos lazos fuertes de solidaridad. ${ }^{24}$ Como la mayoría de los movimientos intelectuales que recorrieron la Europa finisecular, creía firmemente que podría conseguir esa sociedad ideal a través de la educación. De ahí que, en medio de la I Guerra Mundial, y como una evolución de las "New Ideals in Education conferences" iniciadas en 1914 por impulso de la Sociedad Montessori, ${ }^{25}$ se fundase en Inglaterra en 1915 la Theosophical Fraternity in Education, de la cual fue inspiradora y primera secretaria Beatrice Ensor. Ella estaba firmemente convencida de que la nueva educación podía cambiar el mundo, pero no con medidas legislativas, sino transformando la opinión pública, es decir, con una acción de propaganda tal y como la entendían los intelectuales de la posguerra. Para ello necesitaba expandir su mensaje más allá de los círculos teosóficos, un desafío que emprendió con la reconversión de la fraternidad internacional en una New Education Fellowship y con la creación de la revista Education for the New Era en 1920, desde la que se difundirían los llamamientos a participar en el congreso de Calais de 1921. La convocatoria circuló en la prensa pedagógica o general, a través de los periódicos teosóficos y mediante cartas personales enviadas por los que ya se atisbaban principales líderes del movimiento, Adolphe Ferrière y Beatrice Ensor. ${ }^{26}$

En el congreso de Calais se creó la LIEN y se adoptaron los principios que darían unidad doctrinal al movimiento en esos primeros años. Pero también se estableció la

\footnotetext{
${ }^{23}$ En este trabajo no se ha realizado el análisis de la tercera revista del movimiento, Das Werdende Zeitalter, que era el órgano de expresión en los países de lengua alemana, pues ha sido imposible acceder a ella. Se ha revisado el catálogo realizado en 1994, en el que se registraron todos los artículos y recensiones publicados en sus once años de vida (1922-1932), y no se ha encontrado ninguna referencia a España, salvo la reseña de un libro alemán dedicado a Francisco Ferrer y Guardia. Dietmar Haubfleisch y Jörg-Werner Link, Das Werdende Zeitalter (Internationale Erziehungs-Rundschau) (Bonn: Archiv der Arbeiterjugendbewegung, 1994).

${ }^{24}$ Sylvain Wagnon, "Les théosophes et l'organisation internationale de l'éducation nouvelle (1911-1921)", REHMLAC+ 9, no. 1 (2017): 146-180 y Sue C. Middleton, "New Zealand Theosophists in "New Education" networks, 1880s-1938”, History of Education Review 46, no. 1 (2017): 42-57.

${ }^{25}$ John Howlett, "The formation, development and contribution of the New Ideals in Education conferences, 1914-1937", History of Education 46, no. 4 (2017): 459-479.

${ }^{26}$ Condette y Saboye, "Une éducation pour une ére nouvelle", 60.
} 
estructura organizativa en la que se sustentaría ese nuevo cuerpo internacional. Beatrice Ensor mostró su lado más pragmático, pues ella fue la que diseñó el modelo relacional, basado en tres ediciones de su revista, denominada ya The New Era, en lenguas inglesa, francesa y alemana — las dos últimas aún ni existían —; la suscripción a cualquiera de ellas convertiría al suscriptor en miembro de la LIEN. Cada país sería autónomo y las informaciones sobre sus esfuerzos innovadores se publicarían en las tres ediciones. Los tres editores de estas futuras revistas - Beatrice Ensor, Adolphe Ferrière y Elizabeth Rotten - se aseguraron todo el poder, ya que en sus manos descansaba la elección del tema y la organización del congreso bianual del movimiento. ${ }^{27}$

En España la prensa general y las publicaciones pedagógicas no recogieron la convocatoria del congreso de Calais, pero aún así nuestro país fue uno de los doce representados. Y ello sólo se entiende por la pujanza de la Sociedad Teosófica española, dos de cuyos miembros, María Solà Ferrer de Sellares y Attilio Bruschetti, acudieron al Congreso de París de junio de 1920, en el que conocieron a Beatrice Ensor y en el que se sentaron "las bases para el funcionamiento del Trus (sic) Teosófico de la Educación en España". ${ }^{28}$ No sabemos cómo entró en contacto María Solà ${ }^{29}$ con la teosofía ni con la New Education Fellowship; en su autobiografía explica que lo que le llamó la atención de este último grupo fue su insistencia en "la importancia de la educación para evitar hecatombes como la que se había vivido en la guerra mundial" ${ }^{30}$ El movimiento teosófico confiaba plenamente en ella, pues le encargó su proyecto pedagógico, que defendió en marzo de 1921 ante el Consejo de la Sección Española de dicha Sociedad. También formó parte de la delegación que acudió al congreso de la Federación europea de sociedades teosóficas, celebrado en Viena en 1923, y esta presencia permitió "de resserrer les liens entre les théosophes catalans et la Fraternité internationale de l'éducation". ${ }^{31}$

No sabemos nada tampoco de la participación de María Solà en Calais; en su autobiografía superpuso sus recuerdos con los de Viena; por otra parte relató que en ese congreso conoció a los pedagogos más famosos, citando entre ellos a María Montessori, que no acudió a Calais. Según su relato, al ser la única española presente en ese congreso, le insistieron en que aceptara la secretaría general para representar a la NEF en España. Este relato no puede ser cierto, ya que en el Congreso de Calais se creó la LIEN pero aún no se estableció ningún procedimiento para organizar secciones nacionales, si bien algunos países empezaron a constituirlas de manera totalmente autónoma e in-

\footnotetext{
${ }^{27}$ William Boyd y Wyatt Rawson, The Story of the New Education (London: Heinemann, 1965), 72-73.

${ }^{28}$ Vicente Penalva Mora, "El orientalismo en la cultura española en el primer tercio del S. XX. La Sociedad Teosófica Española (1888-1940)" (Tesis doctoral, Universidad Autónoma de Barcelona, 2013), 188-189. Este autor fecha el congreso en 1921, pero debió ser el de París de junio de 1920, al que, según Condette y Saboye, acudieron delegados españoles. Condette y Saboye, "Une éducation pour une ère nouvelle", 49.

${ }^{29}$ Joan Soler i Mata, "María Solà de Sellarès: Teosofía, Educació i Escola Nova a Catalunya", Annals del Patronat d'Estudis Històrics d'Olot i Comarca 21 (2010): 165-182.

${ }^{30}$ María Solà de Sellarès, Irradiación de una biografía (México: Costa-Amic Editores, 1987), 8.

${ }^{31}$ Joan Soler, "Théosophie et éducation en Espagne (1891-1939): espaces de sociabilité et réseaux éducatifs", en Éduquer dans et hors l'école. Lieux et milieux de formation. XVII - XXe siècle, eds. Bruno Garnier y Pierre Kahn (Rennes: Presses Universitaires de Rennes, 2016), 92.
} 
formal. Lo que realmente sucedió lo reveló María Solà en una carta escrita a Ferrière el 10 de abril de 1923: "Nous avons fondé la "Section espagnole de la Fraternité Internationale d'Éducation" lors de mon retour de Calais au mois d'août 1921. Comme j'étais la seule Espagnole qui se fût rendue au Congrès d'Éducation de Calais, je fus nommée presidente" ${ }^{32}$ Está claro que esta fundación y este nombramiento fueron realizados dentro del movimiento teosófico. Esta sección española se presentó como alternativa a la organización del magisterio oficial, se consideraban más legitimados que los maestros públicos para llevar a cabo la renovación pedagógica de acuerdo con los principios de la educación nueva, porque veían a dichos docentes sólo preocupados por mejorar su situación económica, y despreciaban la estructura del sistema educativo, pues no creían en esas leyes aparecidas "en el gran mentidero nacional, ó sea la "Gaceta de Madrid"”. ${ }^{33}$

Adolphe Ferrière no debía estar muy satisfecho con esta predominancia inicial del elemento teosófico en la representación española, y empezó a pedir por su cuenta apoyos morales a la LIEN, que esperaba concretar en un apoyo material más tangible en forma de suscripción a la revista Pour l'Ėre Nouvelle. Para crear el network de amigos españoles de la LIEN Ferrière recurrió a su entramado de relaciones del Instituto J. J. Rousseau, obteniendo la primera respuesta positiva de Pau Vila. Pero fue a Domingo Barnés a quien citó explícitamente como la persona que le proporcionó el listado de todos aquellos renovadores a los que debería dirigir su llamamiento. Y la selección que le trasladó debió ser muy adecuada, porque entre abril y mayo de 1922 se publicaron los principios y finalidades de la LIEN en muchas revistas pedagógicas y en periódicos de información general, destacando en esta labor divulgadora el maestro madrileño Sidonio Pintado Arroyo y el inspector de enseñanza primaria de Santander Vicente Valls y Anglés. Domingo Barnés fue la cabeza más visible de la Asociación Española de Antiguos Alumnos y Amigos del Instituto J.J. Rousseau, creada en 1921 para salvar económicamente al Instituto y ayudar a la difusión en España de sus ideas pedagógicas. ${ }^{34}$ Para ello, y aprovechando las conexiones de Barnés con la editorial La Lectura, iniciaron una línea de publicaciones de obras de los profesores del Instituto, como Claparède y Bovet, extendida hacia otros pedagogos del movimiento de la Nueva Educación, como Decroly, justo después del Congreso de Calais, ${ }^{35}$ además de financiar la visita a España de Claparède

\footnotetext{
32 "Notre Ligue", Pour l'Ére Nouvelle II, no. 7 (1923): 44-45.

${ }^{33}$ Fernando Valera, "Misión de los padres en la educación", El Pueblo: Diario Republicano de Valencia, 18 de octubre de 1922.

${ }^{34}$ Pedro Rosselló, "El Instituto J.J. Rousseau. Sus hombres, su obra. Sugestiones que para nuestro país pueden derivarse de su funcionamiento", Boletín de la Institución Libre de Enseñanza XLVII, no. 759 (1923): 169-171. En este artículo Pedro Rosselló justificó la legitimidad de la Asociación para representar a España en las distintas organizaciones pedagógicas internacionales, y especialmente en la LIEN, por su vinculación al Instituto J.J. Rousseau.

${ }^{35}$ En diciembre de 1921 El Magisterio Español publicó un resumen muy amplio del libro de Decroly y Boon Vers l'école renovée, presumiblemente escrito por Sidonio Pintado, quien debía de estar preparando la traducción de la obra en ese momento. La inclusión del artículo se justificaba por lo muy conocido de los maestros españoles que era ya Decroly, conocimiento que se había producido como consecuencia de su interesante conferencia en el congreso de Calais, conferencia inédita en las revistas españolas. El 20 de marzo de 1922, Pedro Rosselló escribió a Decroly manifestándole su decepción porque ese folleto que había publicado junto con Gerald Boon,
} 


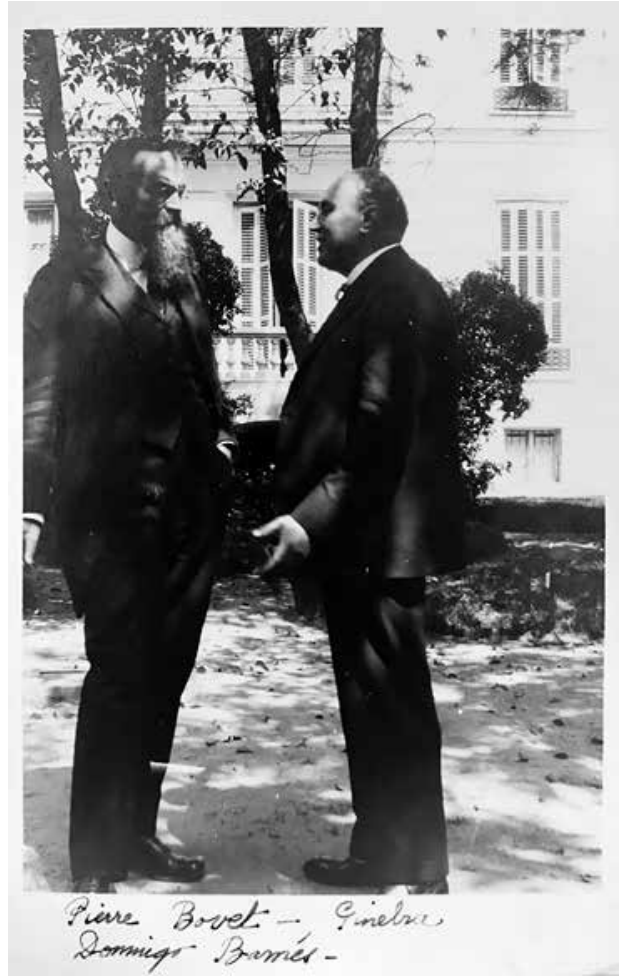

La presencia de educadores y educadoras españolas en Ginebra y en Bruselas, auspiciadas por la JAE, en particular, fue muy relevante. Domingo Barnés (en la foto con Pierre Bovet) y Pedro Roselló, fueron entonces compañeros en este intercambio. Fotógrafo: Rodolfo Tomás y Samper. Archivo de María del Mar del Pozo Andrés.

en mayo de 1923. Precisamente en junio de ese año la Asociación anunció el encargo recibido de "la Liga Internacional en pro de la educación nueva de representarla en España y de procurar que nuestro país esté debidamente representado en el segundo Congreso que dicha Liga organiza en Territet". ${ }^{36}$ Por lo tanto, esta Asociación, compuesta por antiguos alumnos del Instituto J.J. Rousseau de Ginebra, fue el segundo network español que estableció relaciones con la LIEN.

En el verano de 1922 se produjo una intensa comunicación entre educadores españoles y las máximas figuras de la LIEN. El espacio de encuentro fue el III Congreso

y que les había prometido para la colección patrocinada por la Asociación Española del Instituto J.J. Rousseau, estaba ya traducido al castellano. Al final el libro se publicó en La Lectura, pero en versión de Sidonio Pintado y no de Pedro Rosselló, quien en su carta rogaba a Decroly que les enviase otro folleto, para poder ligar su nombre a la obra realizada por la Asociación. Esta es una pequeña muestra de hasta qué punto el mercado editorial movía los hilos de los grupos españoles ligados al movimiento de la Nueva Educación.

36 "Escuelas y Maestros. Congreso Internacional de Educación”, La Libertad, 1 de junio de 1923. 
Internacional de Educación Moral, presidido por Ferrière ${ }^{37}$ y en el que intervinieron muchísimos miembros conocidos de la LIEN, por lo que se consideró una buena plataforma de divulgación de las ideas escolanovistas. A este congreso acudieron 23 educadores españoles, procedentes, en general, de las áreas de Cataluña y Madrid. Por Cataluña asistieron, según Joan Soler, ${ }^{38}$ Alexandre Galí, la maestra de Barcelona Assumpció Portas, Félix Martí Alpera, regente de la escuela práctica aneja a la Normal de Barcelona, el concejal barcelonés Nicolau d'Olwer, el presidente de la Sociedad Económica de Amigos del País Joan Garriga, y los antiguos alumnos del Instituto J.J. Rousseau Pedro Rosselló y Pau Vila. También estuvo presente otro representante catalán, Martí Esteve Guau, quien pronunció una conferencia frente a la exposición de publicaciones y trabajos pedagógicos enviada por la Mancomunitat y el Ayuntamiento de Barcelona. Por Madrid fueron la maestra y la inspectora (hermanas) Pilar y Matilde García del Real, el director del Grupo escolar Cervantes Ángel Llorca, otros directores escolares (Virgilio Hueso, Rodolfo Tomás y Samper y Pilar Oñate), el profesor de la Escuela Superior del Magisterio Anastasio Anselmo González y Fernández, el publicista y director de El Magisterio Españo/ Victoriano Fernández Ascarza, el fundador de los Exploradores de España Teodoro Iradier y Herrero, la profesora de la Escuela Normal de Cuenca Dolores González-Blanco (esposa de Tomás y Samper) la diplomada del Instituto J.J. Rousseau Mercedes Rodrigo Bellido y la música María Rodrigo Bellido. En este congreso pronunció una conferencia Pau Vila sobre "EI internacionalismo y el nacionalismo en la enseñanza de la historia", que terminó con la lectura de un programa de Historia de Cataluña. Su presentación dio lugar a una extemporánea intervención de "uno de los señores de Madrid", quien lanzó un discurso plagado de tópicos patrioteros, el cual fue denunciado y ridiculizado por otro de los asistentes al congreso, el catalanista y escritor valenciano Francesc Almela i Vives. ${ }^{39}$ El suceso debió ser bastante comentado entre los asistentes, y Ferrière tuvo así ocasión de captar, en este congreso, las diferencias abismales de carácter territorial, doctrinal, ideológico, político y pedagógico que separaban a los educadores españoles. De hecho, la idea de la división y el desacuerdo fue ya una imagen que siempre quedó asociada en su mente con España.

En este congreso se conocieron Ferrière y Rodolfo Tomás y Samper, un antiguo alumno de la Escuela Superior del Magisterio, muy interesado en las técnicas psicométricas y en la orientación profesional, es decir, en los estudios psicopedagógicos impulsados por el Instituto J.J. Rousseau. ${ }^{40}$ Ambos experimentaron una corriente de simpatía mutua instantánea; Tomás y Samper le conceptuó como un gran orador y un gran escritor y Ferrière, siempre sensible al halago, creyó encontrarse ante un believer, alguien totalmente entusiasta de la educación nueva y dispuesto a constituir una sección de la LIEN en Ma-

\footnotetext{
${ }^{37}$ Marco Cicchini, "Un bouillon de culture pour les sciences de l'éducation? Le Congrès international d'Éducation morale (1908-1934)", Paedagogica Historica 40, nos. 5-6 (2004): 633-656.

${ }^{38}$ Joan Soler i Mata, "The Rousseau Institute of Geneva's influence on and presence in Catalan pedagogy in the first third of the $20^{\text {th }}$ century", Catalan Social Sciences Review 1 (2012): 75.

${ }^{39}$ Francesc Almela i Vives, "Notas. Sobre el Tercer Congreso Internacional de Educación Moral", La Correspondencia de Valencia, 24 de agosto de 1922.

40 José Moratinos Iglesias, El pensamiento pedagógico del alicantino Rodolfo Tomás y Samper (el pedagogo, el profesor, el hombre) (Alicante: Ayala, 1988).
} 
drid. Parece que durante el congreso Tomás y Samper transmitió a Ferrière el deseo de algunos de sus colegas, profesores de Escuelas Normales, de crear en Madrid un grupo adherido a la LIEN, que se iniciaría con la publicación en 1924 de "une revue soeur de "Pour l'Ère Nouvelle"". ${ }^{41}$ Este proyecto era difícilmente creíble, pues el profesorado normalista había lanzado ya la Revista de Escuelas Normales como un órgano del colectivo y sin pretensiones de integrarse en el movimiento escolanovista. Ahora bien, la noticia debió inquietar a María Solà, quien rápidamente empezó a enviar informaciones sobre la renovación pedagógica en España, que simbolizó en la figura de Rufino Carpena, ${ }^{42}$ un director de una escuela graduada de Barcelona. ${ }^{43}$ Esta elección no debió ser casual, pues con este gesto manifestó su apoyo a la escuela pública y su convencimiento de que también el magisterio oficial era capaz de adentrarse por los caminos de la educación nueva.

A partir de ese momento fue el propio Ferrière el que diseñó cuál iba a ser el entramado de la representación de la LIEN en España. Imaginó un modelo similar al francés, en el que coexistían dos grupos 0 asociaciones de educadores relacionados con el movimiento. El grupo de María Solà sería el paralelo a "L'Éducation nouvelle" de Alice Jovenne en París, es decir, agruparía a los propagandistas, se dirigiría preferentemente a la iniciativa privada, desarrollaría más los métodos de la escuela activa e insistiría "sur le rôle spirituel de l'oeuvre de rénovation à accomplir"; mientras que el grupo de Tomás y Samper se identificaba con el de "La Nouvelle Éducation" de Guéritte y Roger Cousinet, es decir, reuniría a los psicólogos, sería experimental, científico y buscaría "ses points d'appui dans les écoles officielles". ${ }^{44}$ Para entender este planteamiento absolutamente alejado de la realidad educativa española, pues ni Solà ni Tomás y Samper tenían ningún poder de convocatoria entre el profesorado oficial, hay que saber que lo que ambos sí poseían era el control de, al menos, una editorial; en el caso de María Solà, las implicadas en el movimiento teosófico en Barcelona; y en el caso de Rodolfo Tomás, la librería Francisco Beltrán de Madrid; y que ambos prometieron, como acto supremo de propaganda, la publicación de las "preciosas obras" de Ferrière en España. Y, efectivamente, la Fraternidad Internacional de Educación tradujo y publicó la primera obra de Ferrière en castellano, en 1924, y Tomás y Samper tradujo la segunda, tercera y cuarta, editadas por Francisco Beltrán en 1926 y 1927.

Cabe pensar que, con al menos tres grupos interesados en hacerse con la representación absoluta de la LIEN en España, habría una afluencia masiva de educadores de nuestro país al segundo congreso del movimiento, el celebrado en Montreux-Territet del 2 al 14 de agosto de 1923. Nada más alejado de la realidad. Lorenzo Luzuriaga anunció, por sorpresa, que se le había nombrado delegado oficial del Ministerio de Instrucción Pública y Bellas Artes para asistir al congreso, aunque ese nombramiento no apareció

\footnotetext{
41 "Notre Ligue", Pour l’Ėre Nouvelle II, no. 6 (1923): 22.

${ }^{42}$ M.S. (¿María Solà?) Fraternité International d’Éducation (Section espagnole), “Nouvelles d’Espagne. L'oeuvre de Rufino Carpena", Pour l'Ėre Nouvelle II, no. 6 (1923): 34-35.

${ }^{43}$ Bernat Sureda García y Sara González Gómez, "Discurso pedagógico y defensa del magisterio en Rufino Carpena Montesinos", História da Educaçâo 21, no. 51 (2017): 229-251.

44 "Notre Ligue", 44-45.
} 
en la Gaceta de Madrid. Y, desde luego, la noticia fue sorprendente porque Luzuriaga no parecía tener relaciones con el movimiento; a pesar de haber comenzado a publicar su Revista de Pedagogía en enero de 1922, ni una sola mención se había hecho de ella en Pour l'Ére Nouvelle y la primera referencia que apareció, ya en julio de 1924, fue para anunciar la reseña que María Luisa Navarro había realizado de la primera obra de Ferrière traducida al castellano, Transformemos la escuela y, de paso, se aludió al extenso resumen del congreso de Montreux aparecido nueve meses antes. Es bastante probable que Ferrière tuviera una cierta animadversión inicial a Luzuriaga, que se transparentó años después, cuando Ferrière reseñó con bastante retraso su opúsculo sobre Escuelas activas (1925) y dio a entender que Luzuriaga había ignorado en sus trabajos las obras pioneras de síntesis de Ferrière tituladas L'École active (1922) y La Pratique de l'École active (1924) - casualmente las dos traducidas y publicadas por Tomás y Samper pero creyó las explicaciones de Luzuriaga en el sentido de que no las conocía en ese momento, explicaciones, por otra parte, rebatibles con las recensiones de obras publicadas en la Revista de Pedagogía desde 1922. Pero también debemos apuntar la gran amenaza que la publicación española suponía para Pour l'Ėre Nouvelle, pues ambas lucharon desde el primer momento por hacerse con el mercado editorial latinoamericano. Esta es la única explicación posible para comprender la ocultación de Ferrière ¡durante dos años y medio! de la Revista de Pedagogía, surgida para informar al magisterio de los principios y desarrollo de la Nueva Educación, ${ }^{45}$ y este silencio choca dolorosamente con su exaltación de las publicaciones búlgara e italiana y con sus informaciones sobre múltiples conversaciones mantenidas con directores de otras revistas afines al movimiento escolanovista precisamente desde enero de 1922.

Al congreso de la LIEN de 1923 acudieron al menos cuatro españoles: Lorenzo Luzuriaga, Ángel Llorca, Pedro Rosselló y José Fernández Cancela, un político liberal que, en aquel momento, era Delegado Regio de Madrid. Debió de asistir también María Solà, quien seguramente logró reforzar la posición de su grupo, pues después de MontreuxTerritet empezaron a organizarse las primeras secciones nacionales a lo largo de 1924, y precisamente en julio de ese año Ferrière definió por primera vez al grupo de María Solà como sección española de la LIEN, con sede en Barcelona. Rosselló y Luzuriaga pasaron fugazmente por el congreso, éste último no parece que hiciera mucho lobbying, compartió con Ángel Llorca alguna excursión y se despidieron el 8 de agosto, una semana antes del fin del evento. Las crónicas que incluyó en la Revista de Pedagogía eran las traducciones al castellano de los resúmenes de las conferencias que había preparado la LIEN/ NEF, con muy escasas pinceladas personales. Pero Ángel Llorca no se perdió ni una sola sesión y anotó cuidadosamente todas sus impresiones en un diario. ${ }^{46} \mathrm{~A}$ través de su lec-

\footnotetext{
${ }^{45}$ Herminio Barreiro Rodríguez, Lorenzo Luzuriaga y la renovación educativa en España (1889-1936) (A Coruña: ediciós do Castro, 1989), 119.

46 "Diario del II Congreso de Escuelas Nuevas celebrado en Montreux-Territet (Suiza), del 2 al 15 de agosto de 1923. Resúmenes de conferencias, impresiones generales, reflexiones y comentarios", en Ángel Llorca, Desde la escuela y para la escuela. Escritos pedagógicos y diarios escolares, ed. María del Mar del Pozo Andrés (Madrid: Biblioteca Nueva, 2008), 171-186.
} 
tura se intuye que no se sintió identificado con el movimiento, le rechinaban algunos de sus rituales como los devotional meetings y la insistencia en la "dirección moral y religiosa", cuando "el problema general de la educación [...] es una cuestión democrática". ${ }^{47} Y$ las escuelas nuevas le parecieron internados en el campo para gente rica. Pero también descubrió la reforma austriaca de la escuela pública, que intuyó como una de las líneas más novedosas de un movimiento que definió como "los umbrales de un nuevo mundo pedagógico", en el que los educadores españoles podrían entrar inspirándose en Giner de los Ríos y Cossío. ${ }^{48}$ Con esta frase Ángel Llorca se convirtió en uno de los primeros educadores que ligó el escolanovismo y el institucionismo.

Considero que Ángel Llorca constituye uno de los puntos nodales del network de la LIEN española, no sólo por sus múltiples relaciones con dos grupos fundamentales del movimiento internacional - el Instituto J.J. Rousseau y los educadores belgas que trabajaban en torno a Decroly — ${ }^{49}$ sino también por su posición en la intersección de varios caminos de la educación nacional: el institucionismo, el socialismo, el republicanismo, el asociacionismo profesional, el europeísmo y el federalismo. Aunque no pretendió liderar ningún grupo, su papel en la organización de la estructura que debía visibilizar a la educación pública española en la LIEN fue crucial, si bien muy difícil de rastrear, porque la modestia del personaje le impidió dejar constancia escrita de su papel, que vamos a intentar reconstruir en los próximos párrafos.

El grupo de la "alta pedagogía" española, es decir, el núcleo en torno a la ILE, la Junta para Ampliación de Estudios y la Escuela Superior del Magisterio, debieron ser muy conscientes desde el principio de la importancia del movimiento que giraba alrededor de la NEF/LIEN, y no sólo por lo que pudieran leer en las revistas pedagógicas, sino también por sus propias relaciones personales. Cossío recibió información directa de Ángel Llorca sobre el congreso de Montreux-Territet..$^{50}$ José Castillejo era cuñado de Claude Claremont, uno de los más conocidos montessorianos ingleses, quien participó en el Congreso de Calais de 1921 como sustituto de la propia Montessori. Escribía habitualmente en The New Era y debía estar muy cercano a Beatrice Ensor, posiblemente él fue la conexión inglesa que los pedagogos españoles tuvieron con la NEF.

\footnotetext{
${ }^{47}$ Ibidem, 173.

${ }^{48}$ Ángel Llorca, "El Segundo Congreso Internacional de las Escuelas Nuevas. Montreux-Territet (Suiza)", Revista de Escuelas Normales I, no. 8 (1923): 230-233.

${ }^{49}$ En una pequeña biografía publicada con motivo de su jubilación y escrita presumiblemente por Luzuriaga se afirmó que Llorca era una de las personalidades "representativas de nuestro país en las relaciones internacionales en materia educativa". "Ángel Llorca: un maestro", Revista de Pedagogía XV, no. 175 (1936): 327.

${ }^{50}$ Cossío le escribe a Llorca, cuando éste había vuelto ya a Madrid: "Mi enhorabuena por ese nuevo baño de humanismo, único modo de conocer y estimar y gozar nuestro propio rincón, y nuestra alma. Sí, ya me contará $\mathrm{V}^{\mathrm{d}}$, ya que llevo tanto tiempo condenado a reclusión celular española". Tarjeta de Manuel Bartolomé Cossío a Ángel Llorca, San Victorio - Betanzos, 3 de septiembre de 1923. "Viejos Papeles" de Ángel Llorca. Fundación Ángel Llorca.
} 
La relación con Beatrice Ensor se hace visible en 1924, cuando ella publicó una pequeña noticia en The New Era diciendo que "Señor José Castillejo" le había informado oralmente sobre una experiencia muy interesante de coeducación en Madrid, en una escuela pública en la que los alumnos permanecían hasta los diecisiete años, y en la que se habían sustituido los exámenes por informes cualitativos de los maestros. Evidentemente se estaba refiriendo al Instituto-Escuela y el hecho de que fuese una escuela coeducativa le pareció a Beatrice Ensor tremendamente relevante, porque los franceses estaban en ese momento envueltos en un amplio debate sobre el tema y habían afirmado "that co-education is impossible in Latin countries", afirmación que deberían retirar al conocer este centro, por lo que esperaba publicar pronto un artículo en su revista sobre él. ${ }^{51}$ El artículo no llegó jamás, pero en julio de 1925 se divulgó en The New Era la "lista de escuelas nuevas" preparada por la NEF, y la última de ellas es el "Istituto-Escuela" (sic), figurando como secretario "Senor J. Castillejo" (sic), y describiéndose como una escuela secundaria estatal en la que se realizaba "interesting work in Intelligence Tests, which are used instead of examinations for entrance to University". ${ }^{22}$ Como es bien sabido, era Ferrière quién seleccionaba las escuelas nuevas que recibían la acreditación como tales, y, en este caso, la NEF inglesa siguió sus recomendaciones, pero añadió algunas escuelas públicas por su cuenta. Ferrière, casi sin poder ocultar su enfado, publicó en el mismo mes de julio de 1925 su lista de "écoles nouvelles á la campagne", todas ellas privadas, pues no creía que fuera posible incluir escuelas públicas experimentales o renovadas, ya que carecía de criterios de evaluación. ${ }^{53}$

Estos listados se publicaron en un momento estratégico muy importante, justo antes de la celebración del tercer congreso de la LIEN, en Heidelberg. Ángel Llorca llevó la voz cantante de todas las estrategias que se planearon para incrementar la presencia española en ese congreso. En el verano de 1924 realizó un viaje a Inglaterra y visitó las escuelas montessorianas que le recomendó Claude Claremont (al que siempre denomina "el cuñado de Castillejo"). Fue a conocer St. Christopher School en Letchworth, una escuela de inspiración teosófica fundada y dirigida por Beatrice Ensor, que estaba en todos los listados de escuelas nuevas, y en la que trabajaba en aquel momento Claude Claremont. Se entrevistó con Iwan A. Hawliczek, el hombre de confianza de Ensor, un teósofo que era también profesor en Letchworth y secretario de la NEF, con el que desarrolló escasa sintonía personal. Y en este viaje coincidió y conversó largamente con el propio Castillejo, quien le acompañó en algunas de sus visitas. Fruto de estos contactos fue la carta que recibió de la propia Beatrice Ensor, en la que posiblemente le pedía ayuda para divulgar el congreso de Heidelberg en España y para atraer a él a los pedagogos más eminentes de nuestro país. La respuesta de Llorca debió ser malinterpretada por Hawliczek, lo que obligó a intervenir a Ferrière y, aunque no he podido localizar ninguna de las dos cartas,

\footnotetext{
${ }^{51}$ B.E. (Beatrice Ensor), "The Outlook Tower", The New EraV (1924): 81.

${ }^{52}$ New Education Fellowship, "List of Schools", The New Era VI (1925): s.p. Detrás de la referencia se anotaba que, para más información sobre la Nueva Educación en España, se consultase con la señora Solà de Sellarès.

${ }^{53}$ Adolphe Ferrière, “Écoles expérimentales en Europe et en Amérique”, Pour l'Ére Nouvelle IV, 16 (1925): 6-7.
} 
ni la de Ensor ni la de Ferriére, sí que se conserva el borrador con el que Ángel Llorca preparó su respuesta a este último.

En este texto quedan claras las intenciones de Llorca: su deseo fue que Cossío se animase a asistir al congreso de Heidelberg y a impartir una conferencia. Por eso, paralelamente, solicitó y obtuvo una beca de la Junta para Ampliación de Estudios para acudir con todos los maestros del Grupo escolar Cervantes a dicho congreso, con lo que pretendía fuese una acción conjunta: por una parte, Cossío explicaría la labor de la ILE para reformar la educación española, y, por otra, se presentaría el Cervantes como una escuela pública de ensayos, muy cercana a la Nueva Educación, y en la que se había puesto en práctica el ideal institucionista. Pero Cossío no se decidió. Debió hacerse algún intento para que fuese Castillejo el conferenciante que representase a España en esa ocasión. Pero esa posibilidad no cuajó. Estaba claro que Ferrière seguía apostando por Tomás y Samper, aunque ni siquiera lo identificaba correctamente, pues en una ocasión lo denominó "Señor Sampo" ${ }^{54}$ Y, efectivamente, el nombre que apareció en el programa oficial del congreso fue el de Rudolfo T. (sic) y Samper, con una ponencia titulada "The Faculties of the Child and the New Education", pero, como Llorca anotó diligentemente en uno de los márgenes de su copia personal, "no vino".

Ángel Llorca y todos los maestros del Cervantes participaron en el congreso de Heidelberg con entusiasmo y llenaron muchas cuartillas con sus comentarios y opiniones..$^{55} \mathrm{~A}$ través de estas notas se percibe que Llorca estaba muy atento a los cambios organizativos que iba a abordar la NEF/LIEN. Además del elenco del Cervantes, el otro español presente en Heidelberg fue Lorenzo Luzuriaga, quien acudió, al igual que en 1923, como delegado oficial del Ministerio de Instrucción Pública, y también en esta ocasión su paso por el congreso fue rápido, de hecho no llegó a hablar con Ferrière, como éste dio a entender en enero de 1926: "Nous croyons savoir que M. Luzuriaga est venu pour peu de temps au congrès de Heidelberg où il s'est renseigné sur place sur le mouvement d'éducation nouvelle" ${ }^{56}$ Con quien sí conversó bastante Ferrière fue con Ángel Llorca; de hecho le cita entre las personas con las que "s'entretient notamment" en los primeros días del congreso, junto con Kerschesteiner, Geheeb o Amélie Hamaïde. Acabado éste, el grupo del Cervantes asistió al curso de vacaciones en el Instituto J.J. Rousseau, y, durante su estancia en Ginebra, Ferrière le invitó a su casa el 21 de agosto. ${ }^{57}$ En esa reunión le pidió a Llorca que le preparase un informe sobre la situación pedagógica en España, informe que Llorca tardó un año en redactar - y no sabemos si envió -

\footnotetext{
54 "Notre Ligue", Pour l'Ère Nouvelle IV, no. 16 (1925): 2.

${ }^{55} \mathrm{He}$ analizado muchos de estos comentarios en María del Mar del Pozo Andrés, "Introducción”, en Ángel Llorca, Desde la escuela y para la escuela, 41-44 y María del Mar del Pozo Andrés, Justa Freire o la pasión de educar. Biografía de una maestra atrapada en la historia de España (1896-1965) (Barcelona: Octaedro, 2013), 48-54.

56 "Révues Étrangères", Pour l'Ėre Nouvelle V, no. 18 (1926): 18.

${ }^{57}$ R. Gerber y V. Czaka, "Vie et oeuvre d'Adolphe Ferrière (1879-1960). Chronologie de son existence. Première partie: 1879-1936", en https://www.unige.ch/archives/aijjr/sourcesenligne/textes/ (Fecha de consulta: 6 de enero de 2021).
} 
porque la lectura de Pour l'Ére Nouvelle le hizo suponer "que [a Ferrière] no le interesaban mucho las cosas de España" y porque "yo no he ido al extranjero nunca con el propósito de contar lo que aquí hacemos". ${ }^{8}$ Es muy posible que en esas conversaciones Llorca intentara convencerle de que la Revista de Pedagogía era la plataforma más adecuada para representar a la LIEN en España.

A lo largo de 1926 la actitud de Ferrière hacia Luzuriaga y la Revista de Pedagogía cambió radicalmente. Dos fueron los acontecimientos que propiciaron este giro. En primer lugar, el anuncio de que "la sección española" de la LIEN — es decir, María Solà y el el movimiento teosófico - había decidido crear una escuela nueva dirigida por un profesor formado en la St. Christopher School de Letchworth (Ricardo Crespo), que era la primera "école nouvelle à la campagne" existente en España, y cuyos organizadores tuvieron "la délicatesse" de nombrar a Ferrière presidente de honor - en The New Era aparecían él y María Solà como presidentes, ambos al mismo nivel —.${ }^{59}$ Era esta la Escuela Nueva Damón, y lo que más entusiasmó a Ferrière fue que "la puissante Revista de Pedagogía de Madrid que dirige notre ami M. Lorenzo Luzuriaga" ${ }^{60}$ había reproducido en su totalidad el proyecto de creación, lo que demostraba que España seguía con atención el desarrollo de esta escuela. Que Luzuriaga otorgara tanto espacio en su revista a la obra de María Solà fue para Ferrière un símbolo de acercamiento entre los dos grupos que, en su esquema mental, representaban a España en la LIEN, lo cual quiere decir que ya había aceptado que el de la Revista de Pedagogía era uno de ellos. También debió de interpretar el gesto de Luzuriaga como una cortesía a su persona, así es que poco después ya anunció que Luzzuriaga (sic) sería uno de los conferenciantes del siguiente congreso de Locarno ${ }^{61}$ El segundo acontecimiento fue la celebración del centenario de Pestalozzi, en el que la Revista de Pedagogía se adelantó a hacer un llamamiento general a la sociedad española y, además, planificó una construcción de la memoria de Pestalozzi similar a la planteada por el movimiento de la Nueva Educación, presentando al pedagogo suizo como el iniciador de la escuela activa. Por ello, todos los actos apadrinados por los pedagogos madrileños organizados en torno a la Revista de Pedagogía se reseñaron ampliamente en Pour l'Ére Nouvelle, en uno de los artículos más largos que esta publicación dedicó a España y que posiblemente fuera preparado, traducido al francés y enviado por Luzuriaga y su grupo. Sin embargo, las actividades realizadas por Rodolfo Tomás y Samper y una recién constituida Sociedad de Amigos del Niño apenas merecieron una información de ocho renglones, pues planificaron una conmemoración muy oficialista y que identificó a Pestalozzi con pedagogos españoles tradicionales. ${ }^{62}$

\footnotetext{
58 "Carta a Adolphe Ferrière sobre la renovación pedagógica en España. 1927", en Ángel Llorca, Desde la escuela y para la escuela, 187-188.

59 “Espagne”, Pour l'Ėre NouvelleV, no. 23 (1926): 197 y “Escuela Nueva Damón”, The New Era 8, no. 30 (1927): 63.

60 "Nouvelles diverses. Espagne", Pour l'Ėre NouvelleV, no. 21 (1926): 91.

61 "Éditorial. Le Congrès de Locarno", Pour l'Ére Nouvelle V, no. 23 (1926): 148.

${ }^{62}$ María del Mar del Pozo Andrés, "Madrid, febrero de 1927: In Memoriam de Pestalozzi. Las cinco conmemoraciones de un centenario polémico", en La recepción de la pedagogía pestalozziana en las sociedades latinas, ed. Julio Ruiz Berrio al. (Madrid: Endymion, 1998), 453-472.
} 
Justamente un mes después de publicarse el número conmemorativo sobre PestaIozzi, en marzo de 1927, la Revista de Pedagogía se convirtió en una de las publicaciones asociadas a la LIEN, al mismo tiempo que L'Educazione Nazionale de Lombardo-Radice. Éste y Luzuriaga entraron a formar parte del Comité Internacional de la LIEN, constituido desde 1925, cuyos miembros eran, además de Ferrière, Ensor y Rotten, un selecto grupo de pedagogos y los directores de las revistas integradas en el movimiento (en aquel momento, nueve). Ferrière afirmó que fue él mismo quien pidió a Lombardo-Radice que representara a Italia en la LIEN. En el caso de Luzuriaga no explicitó de dónde venía la iniciativa de su designación; éste informó en la Revista de Pedagogía que "por invitación del Comité ejecutivo" de la LIEN (es decir, Ensor, Ferrière y Rotten), la revista "ha sido designada órgano en España de esa Asociación, y su director, miembro de aquel Comité Internacional". ${ }^{63}$ Desde ese mismo momento todos los meses se publicaron en la Revista de Pedagogía los siete principios y los cuatro fines de la Liga, además del Comité Internacional y del listado de revistas asociadas. Y el 2 de abril Lorenzo Luzuriaga convocó una reunión para constituir la sección española de la LIEN y empezar a preparar adecuadamente el cuarto congreso, que se celebraría en Locarno en agosto de 1927. Una nueva etapa en las relaciones entre España y la LIEN acababa de empezar.

\section{Entusiasmo interior e invisibilización exterior (mayo de 1927-1931)}

Para Lorenzo Luzuriaga el lograr colocar a la Revista de Pedagogía como órgano de expresión de la LIEN fue un gran triunfo, pero también es verdad que lo personalizó bastante, identificó prácticamente a la Nueva Educación consigo mismo. Sólo desde una perspectiva de apropiación personal podemos entender el curioso uso de las preposiciones que hizo en la extraña frase que utilizó para explicar su participación en el movimiento: "Como extensión radial de mí mismo represento en España a "Liga Internacional de Educación Nueva"”. ${ }^{64}$ Por eso, desde marzo de 1927 empezó una campaña de divulgación continuada de la LIEN y del congreso, no sólo desde la Revista de Pedagogía, sino también desde las páginas de El Sol, el periódico de la intelectualidad española. Menudearon los elogios de Ferrière en estos meses hacia el que ya era siempre calificado como "notre ami M. Lorenzo Luzuriaga". Sin embargo, había una cuestión de tipo procedimental que realmente nunca se llegó a resolver. Luzuriaga anunciaba en junio que se había reunido "la Sección española de la L.I.E.N" ya constituida desde abril. ${ }^{65}$ Ferrière informaba, también en junio, que en las sesiones del Comité Internacional de la LIEN se examinaría la admisión de varios "groupes nationaux de notre Ligue”, y mencionaba los países pendientes de aceptación. ${ }^{66}$ España no estaba entre ellos. ¿Cuándo se decidió en el Comité internacional la aprobación e integración de esta sección española de la LIEN? Esta será una de las preguntas que planeará a lo largo de este epígrafe.

\footnotetext{
63 "La "Revista de Pedagogía" y la Liga Internacional de Educación Nueva", Revista de Pedagogía VI, 63 (1927): 159.

${ }^{64}$ Ernesto Giménez Caballero, "Visitas literarias. El pedagogo Lorenzo Luzuriaga”, El Sol, 25 de marzo de 1928.

65 "Liga Internacional de Educación Nueva. Sección Española", Revista de Pedagogía VI, no. 66 (1927): 303.

66 "Éditorial”, Pour l'Ėre Nouvelle VI, no 29 (1927): 109-110.
} 
Las discusiones de la autodenominada "Sección Española" en estos primeros meses giraron en torno al congreso de Locarno y se reflexionó sobre su tema central, el concepto de libertad y autonomía en educación, sobre el que se presentaron dos ponencias de Luzuriaga y el inspector segoviano Antonio Ballesteros. En todas las sesiones participaba muy activamente Ángel Llorca, lo cual demuestra su apoyo incondicional a este grupo. Pero cuando llegó el momento de aparecer por Locarno, Luzuriaga renunció por "el cumplimiento de sus deberes oficiales", una excusa poco creíble en el mes de agosto. ${ }^{67} \mathrm{El}$ grupo anglosajón explicó su incomparecencia por "political troubles", las mismas que habían impedido viajar a la mayoría de italianos y españoles. ${ }^{68}$ Ferrière, que tuvo que leer él mismo la ponencia de Luzuriaga, apuntó la necesidad de mantener contactos personales más estrechos con los representantes nacionales de la LIEN, lo cual demostraba su descontento por esta y otras ausencias. ${ }^{69}$ La razón más probable de la desaparición de Luzuriaga debió ser la falta de financiación externa de su viaje; en esta ocasión no parece que ostentase la delegación oficial del Ministerio de Instrucción Pública, que implicaba un apoyo económico, tampoco parece que se nombrase otro representante ministerial, lo que quizás pueda interpretarse como una maniobra de la dictadura primorriverista para evitar la excesiva visibilidad internacional de los pedagogos españoles más renovadores.

A este congreso de Locarno fue, como siempre, Ángel Llorca, junto con dos maestras del "Cervantes" que ya habían estado en el de Heidelberg, Justa Freire y Elisa López Velasco, y otras dos docentes de Madrid y Logroño, María del Pilar Oñate y Concepción Sáinz-Amor, ambas con amplia experiencia en viajes internacionales y asistentes habituales a las reuniones de la LIEN española organizadas por Luzuriaga. También acudió Narcís Masó, que se encontraba realizando una larga estancia en el Instituto J.J. Rousseau y que presentó una comunicación, además de pervivir en la memoria de los congresistas por su "chanson comique". ${ }^{70}$ En Locarno se produjeron tres acontecimientos significativos para el desarrollo futuro de la LIEN y para comprender la posición española en ese network internacional.

El primer acontecimiento significativo fue, por supuesto, el número inmenso de participantes, unos 1.200, pero, sobre todo, que muchos de ellos eran docentes deseosos de contar su experiencia renovadora particular, la mayoría de las veces muy modesta, 0 de presentar en las exposiciones pedagógicas los trabajos de sus alumnos. Este fenómeno había comenzado ya en Heidelberg, pero en Locarno fue más visible y afectaba especialmente a los participantes de naciones centroeuropeas jóvenes surgidas después de la I Guerra Mundial, muchas de ellas incluidas en la categoría de "países latinos". De él se hizo eco Ferrière, al destacar que, además de una debilidad cuantitativa, había una debilidad cualitativa en el sentido de "que nos réalisations d'éducation nouvelle peuvent paraître bien timides", lo cual achacaba al poder asfixiante del Estado en estos países,

\footnotetext{
67 "Liga Internacional de Educación Nueva. Sección Española", Revista de Pedagogía VI, no. 68 (1927): 399.

${ }^{68}$ Boyd y Rawson, The Story of the New Education, 82.

${ }^{69}$ Adolphe Ferrière, "Chronique du Congrès", Pour l'Ėre Nouvelle VI, no. 32 (1927): 262.

${ }^{70}$ Ferrière, "Chronique du Congrès", 263.
} 
que machacaba la individualidad. ${ }^{71}$ Podría pensarse que los maestros españoles asistentes a Locarno empatizarían con las experiencias contadas por otros docentes como ellos y tan parecidas a las suyas, pero no fue así. Narcís Masó pronunció su conferencia, a la que no se le concedieron más de dos renglones en las crónicas del congreso: "M. Maso, ancien directeur d'école à Barcelone, élève de l'Institut J.J. Rousseau à Genève, a fait un exposé de quelques essais d'éducation portant sur le jeu et la mesure du travail scolaire en Catalogne". ${ }^{72}$ Ángel Llorca asistió a ella y no pudo ser más crítico: "Sr. Massot (sic) de Barcelona - Expone la organización de una escuela que quiere ser nueva de Barcelona. Todo ello no vale nada en un Congreso Internacional de escuelas nuevas; parece recordar la manera de trabajar corriente en una escuela de tipo y normas viejas que quiere hacer algo nuevo. Habla de clasificación fantástica de los niños para medir sus adelantos en todas las materias". ${ }^{73}$

El segundo acontecimiento significativo en el congreso de Locarno fue la incipiente presencia de educadores latinoamericanos, con los que deberían haber sintonizado rápidamente los españoles por razones idiomáticas. Aunque no estaba en el programa, se anunció la presencia de la brasileña Laura Lacombe, quien comentó una película sobre actividades renovadoras en escuelas públicas de Rio de Janeiro. Del larguísimo resumen que le dedicó Pour l'Ėre Nouvelle - dos páginas con letra muy pequeña - se deduce que esas escuelas presentaban muchas similitudes con aquellas escuelas españolas comprometidas con un currículum activo y en las que se ensayaban innovaciones como las clases al aire libre, lo que podía haber estimulado a los maestros presentes para divulgar sus propias experiencias. Pero tampoco fue así. Concepción Sáinz-Amor coincidió con Ángel Llorca en que a los congresos de educación nueva se acudía para presentar resultados excelentes, y que no se podían mostrar "clases de completa inmovilidad, y otros varios detalles por el estilo, que a parte de ingleses, norteamericanos y alemanes hicieron sonreír" ${ }^{74}$ Sin embargo, aunque los educadores anglosajones enarcaran las cejas ante estos ensayos, los educadores de lengua francesa y, sobre todo, Ferrière, intuyeron en ellos el enorme potencial que tenían esos países latinoamericanos para asegurar el futuro de la Nueva Educación.

El tercer acontecimiento significativo en el congreso de Locarno es que en la reunión mantenida por el Comité Internacional el 8 de agosto se acordó dar una nueva orientación a las organizaciones nacionales de la LIEN. En cada país podría haber representantes individuales, siempre que fueran reconocidos por el Comité Internacional de la LIEN, 0 bien uno 0 más grupos afiliados a la Liga, que debían renovar su vinculación cada dos años. Estas relaciones - individuos o grupos - parecían suficientemente flexibles, pero se normativizó bastante la creación de secciones nacionales. No se admitía más que una

71 "La participation des pays latins", Pour l'Ère Nouvelle VI, no. 31 (1927): 211.

72 Ibidem, 218.

${ }^{73}$ Notas sueltas de Ángel Llorca sobre asistencia a congresos y a las reuniones del Bureau International de l'Éducation en agosto de 1927. "Viejos Papeles" de Ángel Llorca. Fundación Ángel Llorca.

${ }^{74}$ Concepción Sáinz-Amor, "El Congreso de Locarno. Impresiones personales de una congresista", Revista de Pedagogía VI, no. 70 (1927): 488. 
en cada país. Cada sección debía tener un comité ejecutivo de al menos cinco miembros, enviar un informe anual de sus actividades a la sede central de la NEF y, también, aportar una contribución económica decidida por la propia sección. ${ }^{75}$ Informados por Luzuriaga de la nueva estructura de la LIEN, los educadores madrileños llegaron al siguiente acuerdo: "en vista de que el movimiento de educación nueva no es aún demasiado vigoroso en España, se convino en dejar subsistente la actual organización por grupos locales, con vida autónoma y sin cotizaciones, dejando para más adelante la formación de la Sección nacional' ${ }^{76}$ Entre líneas se podía leer la incapacidad de los educadores escolanovistas españoles para converger en una sola sección, y la imprudencia del grupo madrileño al autodenominarse "sección nacional" sin tener los apoyos necesarios para poder constituirla.

Después del congreso de Locarno el movimiento en torno a la Revista de Pedagogía pasó a llamarse "Grupo de Madrid". Aunque reconocido por Ferrière, no aparece en ningún documento oficial de la NEF. Sí que aparece el "Grupo de Barcelona", al que se consideró constituido después del congreso de Locarno ${ }^{77} \mathrm{Si}$ bien oficialmente era grupo y no sección, también se adueñó del concepto "sección española". ${ }^{78}$ A finales de 1927 se había embarcado en un proyecto para "fomentar la fundación de escuelas nuevas en España, debiendo todas ellas adherirse al movimiento internacional de escuelas nuevas, cuyo centro está en Ginebra". ${ }^{79}$ Por lo tanto, quedó clara su orientación exclusiva hacia la escuela privada. La estructura permitía crear otros grupos con criterios territoriales, y ya se hablaba de la constitución de un "Grupo de Segovia" o un "Grupo de Valencia"; este último llegó a formarse y tuvo una vida muy activa durante los años 1929-1930. Y Rodolfo Tomás y Samper también aprovechó la nueva organización de la LIEN para afirmar que su grupo, considerado como Asociación para el Estudio del Niño y con finalidades principalmente de investigación psicopedagógica, estaba afiliado a la LIEN, y él era "el Delegado", aunque ningún documento publicado 0 inédito avala esta afirmación. ${ }^{80}$ No es de extrañar que Ferrière denunciase, justo después del congreso de Locarno, que tanto en España como en Francia había "plusieurs groupes qui s'ignorent et qui....ignorent la Ligue, du moins officiellement". ${ }^{81}$

El Grupo de Madrid de la LIEN marcó su hoja de ruta desde finales de 1927 y, leyendo entre líneas, se puede advertir ya las disensiones existentes en su seno. Luzuriaga propu-

\footnotetext{
75 “Éditorial", Pour l'Ėre Nouvelle VI, no. 33 (1927): 279-280.

76 "Liga Internacional de Educación Nueva", Revista de Pedagogía VI, no. 71 (1927): 543. La cursiva es mía.

77 "New Education Fellowship Diary, 1920-1952", 24. WEF/A/III/193.

${ }^{78}$ María Solà de Sellarès se presentaba ante los visitantes de la Escuela Nueva Damón como Presidenta de la "Sección Española de la Fraternidad Internacional de Educación", que era la traducción al castellano de la New Education Fellowship y, por lo tanto, la denominación inglesa de la LIEN. Así es que también se había apropiado de la representación absoluta de este organismo en nuestro país. L. García Lorenzana, "Notas de viaje. La "Escuela Nueva Damón" en Barcelona", Crónica Meridional, 7 de agosto de 1927.

79 "Liga Internacional de Educación Nueva", Revista de Pedagogía VI, no. 72 (1927): 591-592.

${ }^{80}$ Rodolfo Tomás y Samper, "La llamada educación nueva sigue su camino triunfal", en Adolfo Ferrière, Problemas de Educación Nueva (Madrid: Francisco Beltrán, 1930), 8.

${ }^{81}$ Ferrière, "Chronique du Congrès", 264.
} 
so, "para intensificar la relación del movimiento pedagógico español con el extranjero", dos actuaciones: invitación a pedagogos europeos para que expusieran en nuestro país, mediante conferencias y clases prácticas, sus ideas y sus métodos educativos; y dar a conocer "en el Extranjero el movimiento pedagógico de España", para lo que convendría "estudiar la proposición hecha por una importante revista de lengua francesa, de dedicar un número extraordinario a la educación nueva de España, como ya se ha hecho con la de otros países". Uno de los asistentes, Virgilio Hueso, director del Grupo escolar "La Florida" de Madrid, marcó una tercera actuación: visitar escuelas innovadoras e impartir conferencias para difundir los principios de la Nueva Educación e interesar a la sociedad en cuestiones pedagógicas. ${ }^{82}$ Esta última fue realmente la acción en la que se implicaron más los miembros del Grupo de Madrid; en los dos años siguientes menudearon los denominados "actos de propaganda pedagógica", es decir, las visitas y charlas en diferentes centros educativos madrileños. Pero fue una actividad con escasa repercusión fuera de la capital, y que no tuvo ninguna resonancia ni en España ni en el extranjero.

El Grupo de Madrid se movilizó también para poner en marcha la primera de las actuaciones, y solicitó a la Junta para Ampliación de Estudios que invitase cada año a un pedagogo europeo de reconocido prestigio. El primero fue el director del Instituto J.J. Rousseau y de la Oficina Internacional de Educación Pierre Bovet, quien permaneció en Madrid del 21 al 27 de mayo de 1928. La estancia siguió una agenda similar a la planificada en el viaje de Claparède de 1923. Además de las conferencias, visitó los centros educativos emblemáticos de Madrid — la Institución Libre de Enseñanza, el Instituto-Escuela y el Grupo escolar Cervantes - , e hizo "grandes elogios de estos centros", viajó a Toledo acompañado de Cossío, lo que le resultó "inolvidable", fue recibido por el ministro de Instrucción Pública, se le ofreció un banquete en el Círculo de Bellas Artes organizado por el Grupo de Madrid de la LIEN y un té en la editorial "La Lectura" que sirvieron para iluminar su estancia. ${ }^{83}$ Confesó que el pedagogo español al que estimaba más era Giner de los Ríos, manifestó públicamente su agradecimiento por las "pruebas de cariño" que continuamente le daban los alumnos de nuestro país que asistían a los cursos del Instituto J.J. Rousseau, ${ }^{84}$ escribió una carta en esperanto para los maestros españoles a petición de "mi amigo" Sidonio Pintado ${ }^{85}$ y declaró que la impresión que se llevaba de España era "excelente, excelente. Gran país. Gran historia, grandes posibilidades" ${ }^{86}$ Hizo lo posible por agradar a sus anfitriones y dejó muy buena imagen, pero no sabemos realmente lo que pensó de su experiencia española, pues nunca escribió sobre ella. ¿Por

\footnotetext{
82 "Liga Internacional de Educación Nueva", 543.

83 "Pierre Bovet", Revista de Escuelas Normales VI, no. 54 (1928): 199 y "Le directeur de I'Institut J.J. Rousseau à Madrid", Pour l'Ėre Nouvelle VII, no. 40 (1928): 58.

${ }^{84}$ Pedro Rosselló, "El Instituto J.J. Rousseau. Una conversación con M. Pierre Bovet", Revista de Escuelas Normales VI, no. 52 (1928): 92-93.

85 "Mr. Pierre Bovet, por indicación del "Magisterio Español", se dirige a los Maestros españoles", El Magisterio Español LXII, no. 8042 (1928): 695 y “Mr. Pierre Bovet”, El Magisterio Español LXII, no. 8047 (1928): 763-764. ${ }^{86}$ César González-Ruano, "Diez minutos con M. Pierre Bovet, director de la Oficina Internacional de Educación de Ginebra", Heraldo de Madrid, 26 de mayo de 1928.
} 
qué él y otros ilustres pedagogos europeos de la LIEN fueron tan reticentes a divulgar sus comentarios y opiniones sobre la realidad educativa de España?

La segunda actuación prevista por el Grupo de Madrid era dar a conocer en el extranjero el movimiento pedagógico español y la mejor forma era organizar un número monográfico dedicado a España en una revista europea. The New Era y Pour l'Ėre Nouvelle habían publicado varios números especiales dedicados a países concretos. Precisamente fue esta última revista la que sugirió el proyecto, y se produjeron conversaciones con Ferrière para preparar un monográfico dedicado a la educación nueva en España, similar al ya aparecido sobre Italia. En las reuniones mensuales del grupo se debió debatir intensamente sobre el contenido de esta publicación, pues se habló de recopilar las experiencias llevadas a cabo por algunas escuelas españolas, como el Cervantes y compararlas con otras extranjeras similares. Luzuriaga publicó en este momento en Pour l'Ėre Nouvelle sus treinta puntos característicos de la nueva escuela pública, un artículo que, en este contexto, podía servir para enmarcar las experiencias innovadoras españolas. ${ }^{87}$ En él seguía fielmente los treinta puntos publicados por Ferrière en 1925, pero realizando una adaptación a la escuela pública claramente mediatizada por las instituciones escolares que él conocía en nuestro país. De hecho, citó explícitamente las tres escuelas que, en su opinión, tenían en España el carácter de "escuelas experimentales", y las tres estaban ubicadas en Madrid: Cervantes, Príncipe de Asturias y el Instituto-Escuela. Sin embargo, de ese proyecto de publicación en Pour l'Ėre Nouvelle nunca más se volvió a hablar; posiblemente los integrantes del Grupo de Madrid fueran incapaces de ponerse de acuerdo sobre qué experiencias renovadoras españolas debían presentarse en el extranjero. De las tensiones que debieron existir en su seno es buen ejemplo la polémica mantenida entre Virgilio Hueso y Lorenzo Luzuriaga en las páginas de la Revista de Pedagogía, a propósito de un artículo escrito por el primero en el que denunciaba cómo, a partir de las teorías extravagantes de algunos pedagogos extranjeros "ya hay quien se cree en posesión de la varita mágica que ha de transformar las escuelas primarias españolas", en clara alusión a Luzuriaga. ${ }^{88}$

En este contexto se anunció para el verano de 1929 el quinto congreso de la LIEN en Elsinore (Dinamarca). Desde la Revista de Pedagogía se animó a la asistencia y participación activa en este acontecimiento, como forma de mostrar "la vitalidad actual de la educación española" ${ }^{89}$ Es verdad que en esta ocasión fue una representación más amplia y variada que en anteriores eventos: a los ya habituales Ángel Llorca, Justa Freire, Elisa López Velasco y Concepción Sáinz-Amor se unieron dos decrolyianos convencidos, Anna Rubiés y Jacobo Orellana, y los inspectores Juan Comas y Regina Lago. Joan Alzina y Lorenzo Luzuriaga estaban anunciados como conferenciantes y al menos el segundo sí que fue en esta ocasión, aunque sólo pudo estar presente en las primeras sesiones.

\footnotetext{
${ }^{87}$ Lorenzo Luzuriaga, "Les trente points caractéristiques de l'École publique rénovée", Pour l'Ėre Nouvelle VII, no. 40 (1928): 145-150.

${ }^{88}$ Virgilio Hueso, "Las innovaciones pedagógicas", Revista de Pedagogía VIII, no. 94 (1929): 454-458.

89 "El próximo Congreso de Educación Nueva", Revista de Pedagogía VIII, no. 90 (1929): 279.
} 
Pero tuvo tiempo para hacer el networking habitual en estos congresos, pues mantuvo largas conversaciones con Maria Montessori, Roger Cousinet, Ovide Decroly y Adolphe Ferrière, que, al menos en el caso de los dos primeros, se concretaron en colaboraciones profesionales futuras. ${ }^{90}$ Desde luego, este año la crónica que hizo del congreso tuvo un tono personal sólo posible por relatar sus propias experiencias. También Jacobo Orellana nos dejó una deliciosa descripción de su viaje hasta Elsinore, en el que compartió parte del camino con Decroly y su colaboradora Amélie Hamaïde, y muy sabrosos comentarios sobre la parte lúdica de estos congresos, que no se quedaban escasos de fiestas, bailes y excursiones.

El informe de Jacobo Orellana nos permite atisbar un espacio de socialización informal que se organizó dentro del congreso: el de los educadores en lengua castellana, quienes se reunieron para intercambiar experiencias. En una convención con 1800 asistentes, dominada por los anglosajones y la lengua inglesa, un puñado de españoles y latinoamericanos llamaba poco la atención. Pero ese grupo era fundamental para mantener el espacio de poder de la tercera lengua del congreso, el francés. A Elsinore fue una nutrida representación de Francia, mucho más numerosa que en los eventos anteriores, y de este congreso, como recalcó su secretario, "the French group" salió notablemente reforzado.$^{91}$ Efectivamente, la NEF/LIEN estableció en Elsinore una nueva organización, con una oficina central en Londres y otra en París, en el Museo Pedagógico, que era "le bureau central pour le pays des langues latines (Amérique du Sud, Espagne, Italie, Portugal, Grèce, Roumanie, etc)" ${ }^{92}$ En el Museo se instaló también la sede del Groupe Français d'Éducation Nouvelle (GFEN) y la de la revista Pour l'Ėre Nouvelle, que justo en 1929, y por expreso deseo de Ferrière, pasó a estar a cargo del Grupo Francés. Así es que, de forma suave y sutil, el Grupo Francés se hizo con el control de los países latinos presentes en la LIEN, que en algunos documentos se identificaban con los de lengua francesa. Ese poder adquirido se plasmó en el encargo de organizar en Francia el siguiente congreso de la LIEN, porque era la mejor forma de promover "the cause of new education in the Latin speaking countries". ${ }^{93}$ Luzuriaga, que seguramente asistió por primera vez en Elsinore a la reunión del Comité Internacional de la LIEN, anunció la convocatoria de ese congreso, que él pensaba tendría un Subcomité en París "y probablemente otro en Madrid", encargado este último de impulsar la asistencia de los países latinoamericanos. Desde su viaje por Sudamérica en los últimos meses de 1928, en el que inició varios contactos con educadores innovadores de Argentina y Chile, Luzuriaga acariciaba la idea de establecer una red de relaciones entre el Grupo de Madrid - o lo que es lo mismo, la Revista de Pedagogía - y los grupos escolanovistas latinoamericanos, y esta le debió parecer una

\footnotetext{
${ }^{90}$ Cousinet le invitó al congreso de Pau de "La Nouvelle Éducation" (diciembre de 1930), al que no pudo ir, por lo que fue el propio Cousinet quien leyó su ponencia, y posiblemente, a raíz del contacto surgido en Elsinore, se convirtió en "el hombre en Madrid" de Montessori.

${ }^{91}$ Boyd y Wyatt, The Story of the New Education, 89.

92 "Historique. La Ligue Internationale d'Éducation Nouvelle", Pour I"Ere Nouvelle XVI, no. 135 (1938): 45. Cursiva en el original.

${ }^{93}$ Reunión del Comité Internacional de la NEF/LIEN, 19 de agosto de 1929, Records of the World Education Fellowship (WEF). WEF/A/III/186.
} 
ocasión de oro, tan buena que, olvidando su habitual moderación expresiva, clamó que "sería suicida desaprovecharla". ${ }^{4}$

En Elsinore se decidieron más cuestiones sobre la organización futura de la LIEN, y una de ellas fue la creación de un "comité consultatif" o "consultative committee", que ostentaría el poder ejecutivo desde agosto de 1931 y del que formarían parte algunos representantes elegidos de las secciones nacionales. El Comité Internacional siguió existiendo, pero con un peso específico mucho menor en la toma de decisiones. La situación de España era un poco irregular, no había pedido nunca su consideración oficial como sección, y en el informe sobre el congreso de Elsinore, elaborado por la estructura anglosajona de la NEF, bajo el epígrafe de "Bureaux, Sections and Groups" aparecía solamente María Solà como representante española, ${ }^{95}$ mientras que en el informe divulgado por Ferrière como responsable de la estructura latina de la LIEN, España estaba representada con una Sección, al frente de la cual figuraba Lorenzo Luzuriaga, y con un Grupo, cuya figura visible era María Solà. ${ }^{96}$ Este planteamiento no era raro, muchos países tenían una organización bicéfala, pero la NEF/LIEN sólo permitía el establecimiento de una sección nacional, y muchos países, después de Elsinore, se aprestaron a regularizar su situación, lo que implicaba la elección de una junta directiva, la redacción de unos estatutos y la presentación de la documentación en alguna de las sedes de la LEN/NIEF, para que la sección fuese reconocida oficialmente por la asociación. Estos fueron exactamente los pasos emprendidos por el Grupo de Madrid: acordó "constituir legalmente la Sección Española de la Liga Internacional de Educación Nueva"; 97 nombró un comité directivo cuyo Presidente de Honor era Cossío, Luzuriaga el presidente efectivo y el resto de vocales provenientes casi todos del Grupo de Madrid; aprobó unos estatutos en los que se denominó a la nueva asociación "Liga Española de Educación Nueva", afiliada a la LIEN y que tenía como objetivo "estudiar y difundir las ideas de la educación innovadora en España";98 y, aunque la intención era la de presentar el expediente constitutivo ante la asociación internacional, no sé si entregó éste en París o en Londres, porque no he encontrado ningún documento con el reconocimiento oficial por parte de la LIEN/NEF. Ahora bien, en el primer informe internacional de la NEF, correspondiente al periodo 1931/1932, España aparecía como Sección Nacional y Barcelona no estaba entre los grupos; sin embargo, en la parte final de informes sobre "Sections and Groups" aparecía la "Section" presidida por Luzuriaga y el "Catalonian Group”, liderado por María Solà. ${ }^{99}$

\footnotetext{
${ }^{94}$ Lorenzo Luzuriaga, "El V Congreso Internacional de Educación Nueva", Revista de Pedagogía VIII, no. 93 (1929): 420.

${ }^{95}$ William Boyd, Towards a New Education. A Record and Synthesis of the Discussions on the New Psychology and the Curriculum at the Fith World Conference of the New Education Fellowship hold at Elsinore, Denmark, in August 1929 (London \& New York: Alfred A. Knopf, 1930), 473.

96 "Éditorial", Pour l'Ėre Nouvelle IX, no. 54 (1930): 1-3.

97 "Liga Internacional de Educación Nueva”, Revista de Pedagogía IX, no. 98 (1930): 93.

98 "Estatutos de la "Liga Española de Educación Nueva”", Revista de Pedagogía IX, no. 103 (1930): 288.

${ }^{99}$ The New Education Fellowship, Report for the period January 1931-June 1932 (Revised November, 1932) (London: The Weardale Press, ¿1932?), 5 y 23. Records of the World Education Fellowship (WEF). WEF/A/l/43.
} 
¿Cuáles eran las relaciones entre los miembros del Grupo de Madrid y los de Barcelona? Con María Solà y su grupo teosófico debían ser inexistentes, pero con los educadores de la escuela pública eran cordiales; Margarita Comas y Felix Martí Alpera formaban parte del comité de redacción de la Revista de Pedagogía y publicaban habitualmente en ella. Lorenzo Luzuriaga era uno de los intelectuales "de Madrid" considerados cercanos a los problemas catalanes, por eso fue uno de los elegidos para formar parte del viaje de hermanamiento con Cataluña de los escritores castellanos en marzo de 1930, al que acudió con Ortega y Gasset, Fernando de los Ríos y Marañón, y fruto del cual fue la resolución que aprobó el Grupo de Madrid de la LIEN en su reunión de 5 de abril en favor del bilingüismo, conceptuado como un principio pedagógico afín a las ideas de la Escuela Nueva y basado en el respeto a la personalidad del niño. ${ }^{100}$ Sin embargo, en el viaje a España de Ferrière en noviembre/diciembre de 1930, el Grupo de Madrid y el Grupo de Barcelona actuaron con estilos diferentes.

Ferrière venía exultante después de recorrer toda Latinoamérica durante varios meses y la estancia en un Madrid frío y lluvioso le debió resultar un contrapunto doloroso a su alegría anterior. Tomás y Samper y Luzuriaga se turnaron para acompañarle en un programa demasiado cargado de actividades y en el que se le obligó a socializar con un excesivo número de personas a las que no conocía. De los centros que visitó, reservó sus mayores elogios para el Cervantes, que le pareció una maravilla, y para su director, Ángel Llorca, quien "a le génie de l'organisation dans le domaine du matériel scolaire, poussé jusqu'aux détails les plus infimes". El Instituto-Escuela claramente le decepcionó, — "c'est une très bonne école du vieux modèle", le confió a su diario —;101 el Colegio de Nuestra Señora de la Paloma, del que Tomás y Samper era director pedagógico, le horrorizó; el Grupo escolar La Florida apenas le llamó la atención, salvo el detalle de que su director, Virgilio Hueso, aparecía junto a él en un foto del congreso de Educación Moral de 1922, y por la ILE debió pasar muy rápidamente y sólo anotó unos datos que le proporcionaron. En sus conferencias encontró al público frío y raro, y ninguna autoridad oficial importante vino a escucharle, aunque estuvo muy arropado por varios antiguos alumnos del Instituto J.J. Rousseau. A unas excursiones le acompañó Samper y a otras el matrimonio Luzuriaga. Evidentemente Samper había intervenido en la organización de la agenda del viaje, pues una de las visitas fue a sus editores de la librería Francisco Beltrán, y otra a la Sociedad de Amigos del Niño, una entidad de muy poco peso en el panorama pedagógico madrileño, en la que saludó a tantos socios que no pudo recordar el nombre de ninguno de ellos para escribirlo en el diario, y en la que le obsequiaron con doce kilos de libros. Aún tuvo tiempo de reunirse con Piaget y Pedro Rosselló, ambos estaban en Madrid en esos días, pero no participaron en ninguna de las actividades programadas. Acudió también a una reunión de la sección española de la LIEN, en la que habló de lo que realmente admiraba del panorama pedagógico español, que era la producción editorial, afirmando incluso que las publicaciones escolanovistas "deberían ser traducidas al francés, por no

\footnotetext{
100 “Liga Española de Educación Nueva”, Revista de Pedagogía IX, no. 100 (1930): 191.

101 "Petit Journal de Ferrière", año 1930, tomos I y II. Agradezco al profesor Joseph Coquoz que me facilitase este documento en el año 1999. En aquel momento estaba en posesión del hijo de Ferrière.
} 
tener equivalente en este idioma". Explicó sus impresiones sobre el movimiento de la Escuela Nueva en los países sudamericanos, citando nombres de instituciones y "educadores más sobresalientes". Y de su opinión sobre las escuelas madrileñas dijo muy poco, pero contundente: había advertido "algunos casos brillantes aislados", pero "no tenían igual desarrollo en la realidad escolar las ideas de la escuela nueva". ${ }^{102}$

La estancia en Barcelona tuvo otro estilo y en el diario se intuye que Ferrière se sintió más cómodo y satisfecho en esos días. Ya había hecho escala en la ciudad el 8 de abril de 1930, antes de iniciar la larga travesía a América, y se encontró con las personas que le debían resultar más cercanas, María Solà de Sellarès y Ricardo Crespo, el director de la Escuela Nueva Damón, con quienes visitó el centro durante al menos dos horas y observó el desarrollo de una asamblea. A su vuelta en diciembre María Solà fue a visitarle varias veces por su cuenta, y se intuye la existencia entre ellos de unos lazos de amistad que iban más allá de lo meramente profesional. El resto de las personas con las que se encontró formaban parte de los núcleos selectos de la pedagogía barcelonesa que giraban en torno al Seminari de Pedagogia y al Patronato Escolar del Ayuntamiento de Barcelona. El plan de visitas que le organizaron estaba muy bien pensado para mostrar a Ferrière la práctica de la escuela activa en Barcelona, recorrió varias escuelas al aire libre (la Escola Bosc del parque del Guinardó, la Escola Bosc de Montjuïc y la Escola del Mar) y de todas ellas hizo comentarios elogiosos en su diario 0 en los libros de visitas. ${ }^{103}$ La diferencia entre la agenda de Madrid y la de Barcelona es que la primera se diseñó pensando en los intereses personales y en los grupos de poder, por eso resultó muy abigarrada y no mostró el bullicioso ambiente intelectual y pedagógico de una ciudad en la que ya se olfateaba el giro republicano; en la segunda se percibía una estrategia clara dirigida a que Ferrière incluyese experiencias catalanas en sus registros de escuelas activas. El pedagogo ginebrino parecía conocer mejor a los anfitriones madrileños que a los barceloneses, sorprende que adjudicara la nacionalidad paraguaya a Félix Martí Alpera.

Quizás Ferrière valorase más el ambiente pedagógico barcelonés que el madrileño, pero nunca lo sabremos porque no escribió ni una sola palabra de su viaje a España, ni siquiera unas breves líneas de agradecimiento en Pour l'Ére Nouvelle. De los centros visitados sólo aparecieron noticias y reseñas del Cervantes de Madrid, reproducidas de otras revistas y a su director, Ángel Llorca, le reservó Ferrière sus más elogiosos comentarios. A pesar de las alabanzas que hizo de las colecciones editoriales españolas dedicadas a la Nueva Educación, apenas se reseñaron unos pocos libros publicados por la Revista de Pedagogía, casi siempre traducciones de autores extranjeros del movimiento, y se ignoraron las obras de pedagogos españoles como Margarita Comas, Antonio Ballesteros, Fernando Sáinz, Sidonio Pintado o Concepción Sáinz-Amor, que adaptaron las ideas y los métodos de la Escuela Nueva para hacerlos más accesibles a los docentes. De hecho, el español que le despertó más curiosidad a Ferrière en los años treinta fue el naturista

\footnotetext{
102 "Liga Española de Educación Nueva", Revista de Pedagogía IX, no. 108 (1930): 572-573.

${ }^{103}$ Joan Soler Mata, "Entre Europa i Amèrica Llatina: Adolphe Ferrière i l'Escola Nova a Barcelona", Temps d’Educació 35 (2008): 229-248.
} 
gallego José Castro Blanco y sus trabajos sobre nutrición. Y este silencio aún es más significativo si se compara con la muchísima atención que dedicó a todas las naciones latinoamericanas, la cantidad de artículos que publicó sobre su viaje a América y las largas reseñas que firmó él mismo de libros en castellano sobre experiencias innovadoras de maestros de esos países. Sin embargo, toda la literatura de la renovación pedagógica que se estaba produciendo en España desde finales de los años veinte, y de la que la Revista de Pedagogía fue plataforma excepcional, no mereció ni un comentario ni un elogio de Ferrière.

Es posible que no guardase muy buenos recuerdos de su viaje a España, y tuviera algún agravio comparativo con respecto a las estancias de sus colegas Claparède y Bovet, que recibieron más reconocimiento de las autoridades educativas del gobierno central. Pero yo creo que las razones principales de su silencio fueron dos. En primer lugar, la obsesión que tenía por recuperar el prestigio internacional y erigirse en el referente de la escuela activa, como muy bien señaló Joan Soler. ${ }^{104}$ En el mundo latinoamericano empezaba a ser comprendido precisamente por las traducciones al castellano que se publicaron en Cataluña y Madrid desde 1924, y necesitaba hacerse con el control del network escolanovista que se estaba organizando en esos países. Y Luzuriaga, con su viaje de 1928, sus contactos, su legitimización como representante de la LIEN y la afinidad idiomática, podía poner en riesgo estos planes. Y no sólo él, otros intelectuales y pedagogos también viajaron a América en los meses previos a la proclamación de la Segunda República con la intención de divulgar el progreso cultural español, y uno de ellos, Rodolfo Llopis, fue acompañado del documental “¿Qué es España?”, en el que se incluía una película de quince minutos sobre el Grupo escolar Cervantes. Por lo tanto, el Ferrière que en 1928 quería publicar un número monográfico sobre la renovación educativa española no era el Ferrière de 1930, mucho más interesado en ser recordado como el Pigmalión pedagógico de los educadores latinoamericanos y deseoso de eliminar interferencias españolas en esta misión. Pero, curiosamente, este Ferrière seguía necesitando el mercado editorial de nuestro país y poder publicar en castellano. Esta necesidad es la segunda razón que explica el silencio de Ferrière. Ante la desunión que mostraban los grupos pedagógicos locales, y el control que cada uno de ellos tenía de las editoriales, prefirió no apoyar a ninguno para no perder el favor del resto, una postura pragmática y que ilustra muy bien la relación utilitaria que unía al círculo ginebrino con los círculos pedagógicos españoles. ${ }^{105}$

En abril de 1931, mes emblemático en la historia de España, la Revista de Pedagogía dejó de publicar la página siempre presente desde marzo de 1927, con los principios y fines de la LIEN, el Comité Internacional y las revistas asociadas. No hubo ningún aconteci-

\footnotetext{
104 Ibidem, 233.

${ }^{105}$ Durante la estancia de Ferrière en Madrid, habló con Domingo Barnés sobre Le Progrès Spirituel, una obra suya que iba a publicar Espasa-Calpe, ya traducida por Rodolfo Tomás y Samper. La edición se retrasó catorce meses, Domingo Barnés no le daba respuestas precisas y el 3 de febrero de 1932 escribió a Samper claramente enfadado y pidiéndole noticias urgentes de la publicación, que "est impatiemment attendu par les nombreux correspondants que j'ai en Amérique latine, et auxquels j'ai parlé de ce livre en 1930".
} 
miento externo que justificara esta decisión. ¿Respondió Luzuriaga al silencio de Ferrière negándole la plataforma propagandística que tanto necesitaba para la LIEN? Educadores presentes en el movimiento desde el principio, como Ángel Llorca, cortaron su suscripción a Pour l'Ėre Nouvelle y ya no volvieron a aparecer por los congresos. Se iniciaba una etapa apasionante en la educación española pero la LIEN no iba a formar parte de ella.

\section{Hacia una Escuela Nueva española (1932-1936)}

La Sección Española de la LIEN estuvo bastante inactiva en 1931. Pareció despertar de su letargo a comienzos de 1932, cuando se anunció el sexto congreso de Niza para ese verano, con un tema, "Educación en un mundo cambiante", que "afecta muy directamente a las reformas introducidas por el Gobierno de la República en la enseñanza", por lo que acordaron presentar "una serie de trabajos en los que se exponga el sentido de esas reformas en relación con la educación nueva y la escuela unificada: laicismo, bilingüismo, preparación universitaria del magisterio, obra social de la escuela, etc". La intención era reunir posteriormente esos trabajos en un volumen que se tradujera al francés y al inglés para divulgar en el extranjero la reforma educativa iniciada en España desde la proclamación de la Segunda República. ${ }^{106}$ Esta es la primera vez que se nota un cierto orgullo y ganas de divulgar en el mundo las innovaciones pedagógicas españolas. La Asociación Nacional del Magisterio Primario, posiblemente por influencia de su junta directiva, en la que figuraba Concepción Sáinz-Amor, estimuló la asistencia entre sus asociados, "en estos momentos de renovación de la Escuela española". ${ }^{107}$

En el congreso de Niza participaron representantes de 53 países, muchos de ellos organizados en secciones nacionales. En una película que la NEF preparó de este evento, titulada "The World Moves On" se mostraban fotogramas de estas delegaciones y el número 29 era "Spain". ${ }^{108}$ Ese simple fotograma revelaba el desconocimiento que tenía la NEF de la situación española, pues realmente el único grupo organizado que acudió a Niza fue el catalán, constituido y financiado por la Generalitat con el objetivo de mostrar todo lo que en materia educativa se estaba haciendo en Cataluña desde la proclamación de la Segunda República. Félix Martí Alpera y Rosa Sensat hablaron de la enseñanza primaria; el primero de las nuevas escuelas del Patronato escolar, que esperaba se convirtieran pronto en "Écoles nouvelles", la segunda de las escuelas al aire libre y la aplicación del método Decroly en ellas. Josep Estalella presentó el Instituto-Escuela de Barcelona, en el que el bilingüismo era una realidad cotidiana. Joaquin Xirau, director del Seminari de Pedagogia de la Universidad de Barcelona, explicó la reforma universitaria y Margarita Comas Camps las nuevas orientaciones metodológicas de la Escola Normal de la Generalitat catalana. La inspectora Josefa Herrera y Alexandre Galí, secretario del Consejo de Cultura de la Generalitat, disertaron sobre el bilingüismo en Barcelona. Anna Rubiés Monjonell explicó las películas que se proyectaron sobre las Escuelas del Mar

\footnotetext{
106 “Liga Española de Educación Nueva”, Revista de Pedagogía XI, no. 122 (1932): 193.

107 "Un Congreso interesante", El Magisterio Nacional 1050 (1932): 13-14.

${ }^{108}$ Records of the World Education Fellowship (WEF). WEF/A/II//188.
} 
y del Bosque. Para las exposiciones escolares se llevaron folletos muy bien editados, con despliegue de fotografías y muchos traducidos al francés, en los que se mostraba la labor cultural realizada en Barcelona. Una observadora imparcial, como Concepción Sáinz-Amor, destacó lo bien elegidos que estaban los conferenciantes, las magníficas exposiciones que realizaron y cómo se cumplió el objetivo de dar "una idea clara y completa de la labor hecha y de lo que se proyecta en el futuro". Y lanzó un mensaje para el resto de España: "Sería muy de desear que el ejemplo cundiera en otras partes que no son Cataluña, porque es preciso darse cuenta que en una época de intercambio universal [...] es preciso ponerse en comunicación con los demás, hace falta dar y tomar para poder depurar y mejorar luego". ${ }^{109}$

La realidad es que, por muy bien organizada que estuviese la delegación catalana, pasó totalmente desapercibida en el congreso. En el libro de actas, que recogió las dos terceras partes de las 150 conferencias expuestas, se publicaron solo las de Estalella, Comas, Martí Alpera y Rosa Sensat, se obviaron las de Galí y Xirau. ${ }^{110}$ Los informes elaborados por los comités consultivos de la NEF mostraron su enfado por el afán de protagonismo de todas las secciones nacionales sin excepción - y parece que identificaron a la delegación catalana con la sección española - . Por el "element of national pride" el programa se sobrecargó, "since the various sections of the Fellowship felt that their particular country had to be represented", así es que acordaron que en próximos congresos no se permitiría a las secciones nacionales intervenir en la organización del programa, para evitar la presentación de "national points of view and ambitions side-tracking it from the main issue". ${ }^{111}$ Sorprende sobre todo el silencio de los representantes franceses de la LIEN. Desde las páginas de Pour l'Ėre Nouvelle Ferrière había proclamado la impaciencia y el interés con el que se contemplaba el movimiento de renovación pedagógica que se preparaba en España con el cambio de régimen, pero las crónicas del congreso no recogieron ni la más mínima referencia a la intervención del grupo catalán. Félix Martí Alpera anotó que Pierre Bovet, en su discurso inaugural, "hace alusión a los Grupos escolares de Barcelona, que ha visitado", citándolos entre un abanico de escuelas nuevas. ${ }^{112} \mathrm{Sin}$ embargo, Martí Alpera no debió llegar a hablar con Ferrière, a pesar de su conocimiento mutuo al menos desde la visita de 1930, pues comenta que lo vio "entre los astros mayores del Congreso [...] con su perfil árabe, más pálido y cetrino que nunca". ${ }^{113}$

\footnotetext{
${ }^{109}$ Concepción Sáinz-Amor, "El VI Congreso internacional de "Educación nueva". Cursos y grupos de estudio", El Magisterio Nacional 1129 (1932): 1-2 y Concepción Sáinz-Amor, "El VI Congreso internacional de "Educación nueva". Exposiciones y films", El Magisterio Nacional 1130 (1932): 1-2.

${ }^{110}$ Rawson, W. ed., New Education Fellowship. Sixth World Conference. Nice. MCMXXXII. Full Report (London: New Education Fellowship, s.a.), 424-431, 432-435, 437-440 y 441-446.

111 "Notes on Fellowship World Conferences with particular reference to Nice and to the 1935 Conference". Records of the World Education Fellowship (WEF). WEF/A/III/188.

${ }^{112}$ Félix Martí Alpera, "EI VI Congreso Mundial de la Liga Internacional de la Educación Nueva", Suplemento a La Escuela Moderna XLI, 3723 (1932): 1252.

${ }^{113}$ Félix Martí Alpera, "El VI Congreso mundial de Educación Nueva", Suplemento a La Escuela Moderna XLI, 3717 (1932): 1160.
} 
El congreso de Niza tenía como gran objetivo visibilizar la presencia del movimiento de la Escuela Nueva en los países latinos, y como en estos el peso del Estado era fuerte, se invitó desde el principio a representantes ministeriales de Francia y Bélgica y se estimuló la asistencia de delegaciones oficiales. En todos los programas preliminares del congreso jamás se anunció la intervención de ningún delegado o representante de España. Pero en las actas finales se incluyó una conferencia de Rodolfo Llopis, el Director General de Primera Enseñanza, titulada "La rénovation de l'école dans I'Espagne Républicaine". ${ }^{114}$ La historia de su participación, contada por él mismo, es realmente rocambolesca. El congreso comenzó el 29 de julio y el viernes, 5 de agosto, al llegar al ministerio, se encontró con un telegrama de Niza diciéndole que le llamarían a las 12 h. Efectivamente, a esa hora le telefoneó uno de los organizadores para invitarle, "en términos cariñosísimos", a que impartiese una conferencia sobre la labor educativa republicana. Aceptó la invitación y anunció que hablaría el 11 de agosto, es decir, el último día del congreso. A Niza llegó el 10, y ya conversó informalmente con "los delegados de Hispanoamérica". Al día siguiente pronunció su conferencia ante mucho público, entre los que encontró "al grupo español" y a "Ios delegados americanos", y también a los representantes de los sindicatos de maestros francés y belga, y los "compagnons de l'Université nouvelle". Llevó una película sobre el "Teatro de Misiones Pedagógicas" y también se encontró hueco y sala para proyectarla, y pudo explicarla en medio de grandes aplausos. Una hora después se volvió a España. ${ }^{115}$

En todos los informes que se escribieron sobre el congreso de Niza se destacó la desorganización y los cambios de agenda, fundamentalmente porque muchos conferenciantes anunciados no pudieron asistir por razones políticas o económicas. No cabe duda de que Llopis vino a cubrir alguno de los huecos que quedaron en el programa. La crisis de 1929 se estaba haciendo notar enormemente en las finanzas de la NEF/LIEN, porque algunas fundaciones privadas que la patrocinaban retiraron la subvención. En estas circunstancias, el tener el apoyo de los gobiernos de los países latinos, mucho más centralizados, era fundamental para el desarrollo del movimiento. Y, además, la experiencia del congreso de Niza demostró que los ministerios de Instrucción afines a la Nueva Educación subvencionaban con liberalidad las iniciativas de la NEF/LIEN. Esta fue la pragmática respuesta que la sección anglosajona dio a Ferrière cuando éste se quejó del incremento en los contactos con el mundo oficial, temiendo que estos contactos apagasen el ideal vitalista del movimiento. Por eso, no es de extrañar que, en las escasas veinticuatro horas que Llopis pasó en Niza tuviera tiempo de hablar con Beatrice Ensor, presidenta del Consejo Internacional de la NEF, con Paul Langevin, presidente del con-

\footnotetext{
${ }^{114} \mathrm{~A}$ esta conferencia se le dio mucha divulgación, publicándose en otro libro y en la revista francesa del movimiento. Rawson, ed., New Education Fellowship, 414-423 (versión en francés, se le cambia a Llopis el nombre de pila, Rodrigo en lugar de Rodolfo); W. Rawson, ed. A New World in the Making. An International Survey of the New Education (London: New Education Fellowship, 1933) (version en inglés: "The renovation of the school in Republican Spain) y Rodolfo Llopis, "Congrès de Nice. La Rénovation de l'école dans l'Espagne républicaine", Pour l'Ėre Nouvelle XII, no. 84 (1933): 3-9.

115 "La nueva educación. Rodolfo Llopis en Niza" (de El Socialista), Trabajadores de la Enseñanza II, no. 29 (1932): 1-2.
} 
greso de Niza, y con Émilie Flayol, secretaria del GFEN. Todos le propusieron celebrar el próximo congreso de la NEF/LIEN en España, o eso pensó él. Así quedó acordado y Llopis se volvió a Madrid convencido de que había conseguido un gran éxito para nuestro país.

Y en este tablero de ajedrez que fue Niza, ¿dónde estaba Luzuriaga? No parece que se le nombrara delegado oficial del ministerio, pero es posible que pensara asistir al congreso, pues hasta el mes de agosto no informó de que "retenido por otras ocupaciones" no había podido estar en Niza, a pesar de que "tenía reservada en él una conferencia",116 pero su nombre jamás se mencionó en los programas previos del congreso. En los meses posteriores, Rodolfo Llopis fue invitado a París y Bruselas a hablar sobre la renovación pedagógica republicana y se convirtió en uno de los nombres que más se identificaba en Europa con la Nueva Educación española. El 21 de octubre de 1932 se constituyó en el Seminari de Pedagogia de la Universidad de Barcelona la Lliga d'Educació Nova como sección de la LIEN, "representación catalana de The New Education Fellowship" y se nombró presidenta a Margarita Comas. ${ }^{117}$ Está claro que se sintió marginado y ninguneado por unos y por otros y muy poco tiempo después dimitió como presidente de la Sección Española de la LIEN. Aunque nunca informó de esta dimisión en la Revista de Pedagogía, debió producirse en la primavera de 1933, pues la justificó por su nombramiento para la Secretaría Técnica del Ministerio de Instrucción Pública, y ocupó este puesto por Orden de 26 de abril. En todas las informaciones oficiales producidas por la LIEN/NEF se afirmó que no se había decidido aún su sucesión, y en el informe de 1932-1933 seguía figurando la Sección Española, sin presidente, y el "Catalonian Group", dirigido por María Solà. ${ }^{118}$ Sin embargo, en el de 1934-1936 se comunicó que "the Barcelona Section", creada en 1933, "now represents the whole of Spain, the Madrid Section having ceased to exist. The group in Barcelona under the leadership of Señora Sellares has combined with the Section" 119 y se había logrado una dirección integrada: la presidenta de la Sección era Margarita Comas y la secretaria María Solà.

La LIEN/NEF entendió que esa nueva Sección Española ostentaba la representación nacional, de hecho, en todos los documentos posteriores se fijó 1933 como fecha fundacional de esta Sección, olvidándose la trayectoria de las etapas anteriores. Y, efectivamente, la Revista de Pedagogía informó que el comité directivo de la Sección Española de la LIEN radicaba en Barcelona, lo presidía Margarita Comas y formaban parte de él, "como representantes de Madrid", Lorenzo Luzuriaga y Antonio Ballesteros. ${ }^{120}$ En la sesión de constitución "de la Liga en su nueva forma", celebrada en diciembre de 19330

\footnotetext{
116 “Noticias. España”, Revista de Pedagogía XI, no. 128 (1932): 383.

${ }^{117}$ María Ángeles Delgado Martínez, "Margarita Comas Camps (1892-1972), científica y pedagoga", en Margalida Comas Camps (1892-1972), científica i pedagoga, ed. María Ángeles Delgado Martínez (Palma de Mallorca: Govern de les Illes Balears, 2009), 102.

118 "The New Education Fellowship — Sections and Groups. Report June 1932-33". Records of the World Education Fellowship (WEF). WEF/A///43 y "Activité de la Ligue Internationale pour l'Éducation Nouvelle. Année 1932-1933", Pour l'Ėre Nouvelle XII, no. 92 (1933): 266.

${ }^{119}$ New Education Fellowship, Report for 1934-1936 (London: The Leighton Printing, ¿1936?), 43. Records of the World Education Fellowship (WEF). WEF/A/l/43.

120 "Noticias. España”, Revista de Pedagogía XII, no. 144 (1933): 575.
} 


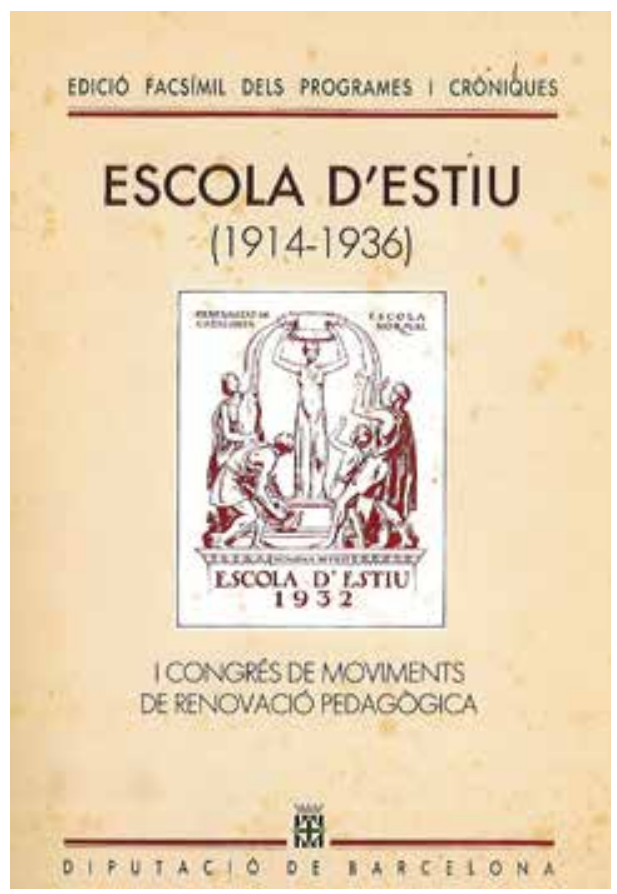

Las Escuelas d'Estiu convocadas con el patrocinio de la Generalitat posibilitaron la presencia en España de figuras como Montessori, Decroly, Piaget o Freinet, al tiempo que llegaron a Madrid Ferrière y Bovet para tomar contacto con el profesorado renovador español y catalán.

enero de 1934, se determinó fijar una cuota para los socios, según exigía la NEF/LIEN; aceptar los idiomas castellano y catalán, indistintamente, para la comunicación entre los miembros; y publicar las decisiones en la Revista de Pedagogía de Madrid y en la de Pedagogía i Psicología de Barcelona. ${ }^{121}$ No debió ser fácil llegar a acuerdos entre todas las partes implicadas, y la vida de esta Sección transcurrió entre interrupciones, pues en 1935 suspendió sus actividades por la situación política, y la desintegración final, anunciada en los informes de la NEF de 1936-1937. ${ }^{22}$

En esos meses de paso de la Sección de Madrid a Barcelona tuvo que decidirse una cuestión importante: la organización de un congreso de Educación Nueva en España. Ésta fue la propuesta que le hicieron a Llopis en agosto de 1932, pero no la entendió del todo bien. En la reunión del comité ejecutivo de la NEF celebrada en Niza el día 8 se acordó extender los periodos para la celebración de los congresos generales y organizar en los años intermedios reuniones por proximidad geográfica 0 afinidad lingüística, sugiriéndo-

\footnotetext{
121 “Liga de Educación Nueva”, Revista de Pedagogía XIII, no. 146 (1934): 94.

122 "New Education Fellowship. Report June 1936 - December 1937". Records of the World Education Fellowship (WEF). WEF/A///43.
} 
se, por iniciativa del grupo latino, que una de ellas podría ser la "Latin speaking conference in Spain". ${ }^{123}$ No se sabe quiénes componían ese "grupo latino", pero la entidad que tomó la iniciativa y a la que se encargó la preparación del congreso fue el GFEN, que, ante el entusiasmo manifestado por "M. Lloppis" (sic) se puso en marcha e incluso decidió ya el tema. ${ }^{124}$ Luego montaron una reunión en París con Luzuriaga, como representante ya dimisionario - de la Liga en España, en junio de 1933, en la que participaron, entre otros, Paul Langevin, Henri Wallon y Émilie Flayol. Luzuriaga quedó encargado de buscar personalidades interesadas, estudiar el lugar y la fecha y recabar subvenciones. Da la impresión de que a Luzuriaga la propuesta no le entusiasmó, porque la única acción directa que emprendió fue preguntarse en la Revista de Pedagogía si el proyecto contaría "la aprobación de un número suficiente de educadores españoles", para lo que recabó la opinión de sus suscriptores. En caso de encontrar respaldo suficiente, buscaría el apoyo oficial; si no se sentía refrendado, "declinaríamos el honor que se nos ha hecho de encargarnos de la organización del Congreso en España y propondríamos que se celebrara en París". ${ }^{125}$

Demasiado bien sabía Luzuriaga que no iba a encontrar ningún apoyo entre los educadores españoles para liderar esa propuesta. En los últimos años había tenido algunos desencuentros con diferentes grupos de maestros, a veces con alusiones muy personales. Quedándonos en el terreno profesional, sobre él había recaído frecuentemente la acusación de ser "pedagogo de gabinete", la misma que se le hizo a Giner a finales del siglo XIX. Los docentes cuestionaban su legitimidad para opinar sobre innovaciones por su alejamiento de la práctica escolar, por su desconocimiento de la realidad cotidiana del aula. Pero, además, la mayoría de los educadores españoles se resistían a convertirse en followers de un pedagogo o metodología escolanovista y a seguirla fielmente; eran más partidarios de adaptar y combinar diferentes prácticas para llegar a construir un método personal. Por otra parte, se notaba ya en esos momentos un cierto rechazo y cansancio hacia la pedagogía extranjera de la Nueva Educación, incluso por parte de maestros progresistas, que empezaba a atisbarse en artículos reclamando una "escuela española", muchos de los cuales reivindicaban la mayor legitimidad de Giner y Cossío frente a los "pedagogos exóticos" para construir una tradición pedagógica autóctona.

Efectivamente, Luzuriaga encontró "poco eco" a su propuesta y rechazó la oferta de organizar el congreso. Comunicó al Grupo Francés que las autoridades catalanas estaban en mejor posición de llevar a buen puerto esta empresa y les puso en contacto con Margarita Comas. Está claro que Luzuriaga y Comas mantenían una relación muy fluida, porque hablaron previamente y debieron llegar a algunos acuerdos, entre ellos, el de que, si el congreso se celebraba en Barcelona, los asistentes harían una excursión a

\footnotetext{
123 "At a meeting of the members of the Executive Board of the New Education Fellowship, held at the Lycée du Parc Imperial, Nice, on Monday, August $8^{\text {th }}, 1932$, at 10.30 a.m.". Records of the World Education Fellowship (WEF). WEF/A/I/34.

124 "Rapport sur l'activité du Groupe Français d'Éducation Nouvelle pendant l'année 1933", Pour l'Ėre Nouvelle XIII, no. 96 (1934): 68.

125 “Liga Internacional de Educación Nueva. Sección Española”, Revista de Pedagogía XII, no. 138 (1933): 286.
} 
Madrid para visitar los nuevos grupos escolares "y celebrar alguna reunión en la capital de la República". ${ }^{26}$ Margarita Comas comunicó en octubre de 1933 al Grupo Francés que el Ayuntamiento de Barcelona apoyaría el congreso. Pero las elecciones generales de noviembre y el triunfo de las derechas, dio al traste con el proyecto, algo que se vivió como una decepción y un fracaso en el lado francés, pero con bastante tranquilidad por parte española.

Y es que las relaciones entre los grupos escolanovistas de los dos países eran poco fluidas, a diferencia de lo que sucedía en otras redes de sociabilidad magisteriales, como los sindicatos o las asociaciones profesionales. Desde que el GFEN se hizo cargo de la revista Pour l'Ére Nouvelle las colaboraciones extranjeras disminuyeron, y eso a pesar de que los responsables repetían cada año su interés de que siguiera siendo "I'organe international des pays de langue latine". ${ }^{127}$ Pero después del congreso de Niza la revista adquirió un marcado carácter francés y perdió muchos suscriptores internacionales. Año tras año, y a medida que las cifras empeoraban, se apelaba más a las relaciones con los países de América del Sur porque "nous espérons pouvoir augmenter notre clientèle, surtout en Amérique latine". ${ }^{128}$ Ese deseo les tenía que crear una cierta competencia con la Revista de Pedagogía y, de hecho, en los años treinta apenas se escribieron reseñas sobre artículos publicados en ella, a pesar de ser una revista afiliada a la LIEN y de la mucha información que ofrecía sobre experiencias prácticas de escuela activa realizadas por maestros, el tema que más interesaba a Pour l'Ėre Nouvelle. El año que ésta tuvo más suscriptores - 804 - fue en 1933, y ese mismo año la Revista de Pedagogía anunciaba que había llegado a una tirada de 4000 ejemplares, y que ese aumento se debía a los docentes jóvenes y a los educadores latinoamericanos. Por otra parte, los escasos artículos y noticias que se ofrecieron en Pour l'Ėre Nouvelle sobre España a partir de 1932 muestran la retórica del imperialismo escolanovista, que tendía a catalogar a todo país o educador considerado "menor" como fiel seguidor de alguna de las grandes figuras del movimiento, en el caso español, Decroly. Un ejemplo de esta retórica lo encontramos en el discurso de Langevin, quien afirmó que Llopis había sido "disciple" de Decroly y "s'est grandement inspiré de ses méthodes dans le vaste et intelligent programme d'organisation scolaire que le gouvernement républicain est en train de réaliser". ${ }^{129}$

El último ejemplo de la escasa sintonía existente entre los grupos escolanovistas franceses y españoles lo encontramos durante la preparación del siguiente congreso de la NEF/LIEN, el de Cheltenham, que se celebraría en julio de 1936. El programa se iba componiendo con propuestas de la NEF y algunas que llegaban del GFEN. Así sucedió en la organización del symposium "on freedom and democracy", en el que los franceses su-

\footnotetext{
126 "Liga Internacional de Educación Nueva", Revista de Pedagogía XII, no. 140 (1933): 382.

127 "Rapport sur l'activité du Groupe Français d'Éducation Nouvelle pendant l'année 1935", Pour l'Ėre Nouvelle XV, no. 116 (1936): 75.

${ }^{128}$ Émilie Flayol, "Rapport sur l'activité du Groupe Français d'Éducation Nouvelle pendant l'année 1934", Pour l'Ére Nouvelle XIV, no. 106 (1935): 69.

129 "Discours de Monsieur Langevin prononcé à la cérémonie commemorative en l'honneur du Docteur Decroly (Bruxelles, 2 juillet 1933), Pour l'Ére Nouvelle XII, no. 91 (1933): 220.
} 
girieron un nombre y el grupo de la NEF añadió "a Spaniard". Fueron los ingleses quienes se encargaron de invitar al español, Salvador de Madariaga, y cuando éste no aceptó, le propusieron que al menos escribiera un corto artículo para la presentación del congreso. ${ }^{130}$ El 31 de julio de 1936 Ferrière estaba ya en Cheltenham, y citó a las personas que se encontró en su camino: Mme. Solà de Sellarès, de Barcelona, Mlle. Amor y Mme. Cornas (sic) de España. ${ }^{131}$ Evidentemente, el único nombre que escribía perfectamente era el de María Solà, a pesar de que Concepción Sáinz-Amor era una habitual de estos congresos y Margarita Comas era la presidenta de la Sección Española.

\section{Conclusión: Sí, hubo un movimiento de Escuela Nueva en España, pero nadie construyó su relato}

El recorrido en las etapas e hitos en la relación de los educadores españoles con la NEF/LIEN nos devuelve a la pregunta inicial, ¿por qué el movimiento español de Escuela Nueva fue invisible en los espacios de encuentro internacionales de los años veinte y treinta? Y, a lo largo del artículo se han destacado tres explicaciones de esta invisibilidad.

La que posiblemente sea la razón más importante fue la desunión de los educadores y los grupos españoles implicados en el movimiento. En sus comienzos no aparecieron sociedades científicas o instituciones que quisieran/pudieran liderarlo; la candidata más clara, que era la Revista de Pedagogía, no tuvo fácil el hacerse con la representación de la NEF/LIEN; las diferencias territoriales e ideológicas impidieron realizar un trabajo común; y la imagen que se transmitió al exterior fue de conflicto y desintegración. El problema no estuvo en la existencia de varios grupos, esto era habitual en muchos países, sino en el mensaje que transmitieron de un entendimiento imposible entre ellos. Cuando finalmente llegó el acuerdo mutuo era ya demasiado tarde.

La segunda razón fue la visión pobre e instrumental que del movimiento de la Nueva Educación española tenían los representantes europeos. Pocos países enviaron a tantos educadores al extranjero como España, y este hecho contribuyó inmensamente a la renovación pedagógica de nuestro país, pero no a su proyección internacional. Las figuras de la LIEN agrupadas en torno al Instituto J.J. Rousseau, y especialmente Ferrière, vieron en España un gran mercado editorial para poder divulgar su obra en castellano y llegar a unas audiencias mucho más amplias en Latinoamérica. España fue el mediador, el intermediario, y por eso no adquirió una identidad propia como productor de conocimiento pedagógico, se quedó en el papel de transmisor.

La tercera razón fue la incapacidad de los educadores españoles para construir y transmitir un relato propio sobre el movimiento de la Escuela Nueva en nuestro país. Se sabía que esta tarea era muy importante, ya lo intentó Pau Vila en los primeros años

\footnotetext{
130 "Minutes of a meeting of the advisory sub-committee of the New Education Fellowship held on the $30^{\text {th }}$ April at 2 p.m." $y$ "A meeting of the Advisory sub-committee of the New Education Fellowship was held on Friday, $27^{\text {th }}$ March, 1936". Records of the World Education Fellowship (WEF). WEF/A/I/34.

${ }^{131}$ Gerber y Czaka, "Vie et oeuvre d'Adolphe Ferrière (1879-1960)".
} 
del siglo XX y casi todos los escolanovistas advirtieron, en un momento 0 en otro, de la necesidad de divulgar en el extranjero lo que se hacía en España. Muchos factores debieron influir en esta muralla comunicativa, desde las dificultades idiomáticas hasta el rechazo de los maestros más conocidos por "vender" una labor que ellos creían no tenía nada de especial. Es verdad que las revistas francesa e inglesa de la NEF/LIEN publicaron muy poco sobre España, pero también es cierto que desde España no se les debió enviar ningún artículo para su divulgación. Faltó una figura con ganas, capacidad y valor para historiar el presente del movimiento, algo muy difícil porque implicaba ser muy independiente y estar dispuesto a enfrentarse con muchos grupos de presión.

Esa es la labor que los hombres y mujeres de la Nueva Educación española nos legaron a los historiadores actuales, la de recuperar y contar su historia a las generaciones futuras, una historia que estuvo marcada en muchas ocasiones por la incomprensión y la desunión, pero que no puede hacernos olvidar la ilusión común que alimentaron todos estos educadores de construir un mundo mejor.

\section{Bibliografía}

Abiss, Jane. "The 'New Education Fellowship' in New Zealand: Its Activity and Influence in the 1930s and 1940s." New Zealand Journal of Educational Studies 33, no. 1 (1998): 81-93.

Aldrich, Richard. The Institute of Education, 1902-2002. A centenary history. London: Institute of Education, 2002.

Aldrich, Richard. "The New Education and the Institute of Education, University of London, 1919 - 1945." Paedagogica Historica 45, nos. 4-5 (2009): 485-502.

Barreiro Rodríguez, Herminio. Lorenzo Luzuriaga y la renovación educativa en España (1889-1936). A Coruña: Ediciós do Castro, 1989.

Beauguitte, Laurent. "L'analyse de réseaux en sciences sociales et en histoire: vocabulaire, principes et limites." En Le réseau. Usages d'une notion polysémique en sciences humaines et sociales, eds. Rosemonde Latricot al., 9-24. Louvain: UCL Presses Universitaires de Louvain, 2016.

Boyd, William y Wyatt Rawson. The Story of the New Education. London: Heinemann, 1965.

Brehony, Kevin J. "A New Education for a New Era: The Contribution of the Conferences of the New Education Fellowship to the Disciplinary Field of Education 1921 1938." Paedagogica Historica 40, nos. 5-6 (2004): 733-755. 
Breure, Abraham S.H. y Heiberger, Raphael H. "Reconstructing science networks from the past. Eponyms between malacological authors in the mid-19th century." Journal of Historical Network Research 3 (2019): 92-117.

Cicchini, Marco. "Un bouillon de culture pour les sciences de l'éducation? Le Congrès international d'Éducation morale (1908-1934)." Paedagogica Historica 40, nos. 5-6 (2004): 633-656.

Cicchini, Marco. "Acteurs et réseaux des sciences de l'éducation: du local à l'international." En Emergence des sciences de l'éducation en Suisse, à la croisée de traditions académiques contrastées. Fin du $19^{\circ}$ - première moitié du $20^{e}$ siècle, eds. Rita Hofstetter, Bernard Schneuwly al., 345-374. Berne: Peter Lang, 2007.

Clews, Christopher. "The New Education Fellowship and the reconstruction of education: 1945 to 1966." Tesis doctoral, Instituto de Educación, Universidad de Londres, 2009.

Clews, Christopher. "Decline and renewal: The New Education Fellowship (NEF) 19451955." History of Education Researcher 88 (2011): 62-71.

Condette, Jean-François y Antoine Savoye. "Une éducation pour une ère nouvelle, le congrès international d'éducation de Calais 1921." Études Sociales 163 (2016): 43-77.

Cunningham, Peter. "The Montessori Phenomenon: Gender and Internationalism in Early Twentieth-Century Innovation." En Practical Visionaries: Women, Education and Social Progress, 1790-1930, eds. Mary Hilton y Pam Hirsch, 203-220. London: Longman, 2000.

Cunningham, Peter. "Innovators, networks and structures: towards a prosopography of progressivism." History of Education 30, no. 5 (2001): 433-451.

Delgado Martínez, María Ángeles. "Margarita Comas Camps (1892-1972), científica y pedagoga." En Margalida Comas Camps (1892-1972), científica i pedagoga, ed. María Ángeles Delgado Martínez, 47-136. Palma de Mallorca: Govern de les Illes Balears, 2009.

Fitzgerald, Tanya, Elizabeth M. Smith, eds., Women Educators, Leaders and Activists: Educational Lives and Networks, 1900-1960. Houndmills, UK: Palgrave Macmillan, 2014.

Fuchs, Eckhardt. "Networks and the History of Education." Paedagogica Historica XLIII, no. 2 (2007): 185-197. 
Fuchs, Eckhardt, Lindmark, Daniel y Christoph Lüth, eds., "Networks and the History of Education." Paedagogica Historica 43, no. 2 (2007): 185-294.

Graham, Patricia A. Progressive Education from Arcady to Academe: A History of the Progressive Education Association 1919-1955. New York: Teachers College Press, 1967.

Gutek, Gerald L. y Patricia A. Gutek. Bringing Montessori to America. S.S. McClure, Maria Montessori and the Campaign to Publicize Montessori Education. Tuscaloosa: The University of Alabama Press, 2016.

Gutierrez, Laurent. "La Ligue Internationale pour l'Éducation Nouvelle. Contribution à l'histoire d'un mouvement international de réforme de l'enseignement." Spirale. Revue de Recherches en Éducation 45 (2009): 29-42.

Gutierrez, Laurent. "Les premières années du Groupe Français d’Éducation Nouvelle (1921-1940)." Recherches \& Éducations 4 (2011): 27-39.

Haenggeli-Jenni, Béatrice. "Pour l'Ére Nouvelle: une revue carrefour entre science et militance (1922 - 1940).” Tesis doctoral, Universidad de Ginebra, 2011.

Haenggeli-Jenni, Béatrice. "Savoirs constitués et programmes scolaires: débats au cœur de la revue Pour l'Ėre Nouvelle (1922-1940)." Recherches \& Éducations 4 (2011): 13-25.

Haenggeli-Jenni, Béatrice. L'Éducation nouvelle entre science et militance. Débats et combats à travers la revue Pour l'Ėre Nouvelle (1920-1940). Berne: Peter Lang, 2017.

Haenggeli-Jenni, Béatrice y Rita Hofstetter. "Pour l'Ére Nouvelle (1922 - 1940). La science convoquée pour fonder une Internationale de l'Éducation." Carrefours de l'Éducation 31 (2011): 137-159.

Hameline, Daniel. "Les premières années de Pour l'Ėre Nouvelle: militantisme et propagande?" Les Sciences de l'éducation - Pour l'Ėre nouvelle 35, no. 4 (2002): 27-40.

Haubfleisch, Dietmar y Jörg-Werner Link. Das Werdende Zeitalter (Internationale Erziehungs-Rundschau). Bonn: Archiv der Arbeiterjugendbewegung, 1994.

Hofstetter, Rita. Genève: creuset des sciences de l'éducation (fin du XIXe siècle - première moitié du XXe siècle). Paris: Librairie Droz, 2010. 
Howlett, John. "The formation, development and contribution of the New Ideals in Education conferences, 1914-1937." History of Education 46, no. 4 (2017): 459-479.

Jenkins, Celia M. "The professional middle class and the social origins of progressivism: A case study of the New Education Fellowship, 1920-1950". Tesis doctoral, Instituto de Educación, Universidad de Londres, 1989.

Jenkins, Celia M. "New Education and its Emancipatory Interests (1920-1950)." History of Education 29, no. 2 (2000): 139-151.

Koslowski, Steffi. Die New Era der New Education Fellowship: Ihr Beitrag zur Internationalität der Reformpädagogik in 20. Jahrhundert. Bad Heilbrunn: Julius Klinkhardt, 2013.

Lawn, Martin. "The institute as network: the Scottish Council for Research in Education as a local and international phenomenon in the 1930s." Paedagogica Historica 40, nos. 5-6 (2004): 719-732.

Lawson, M.D. "The New Education Fellowship: The formative years." Journal of Educational Administration and History 13, no 2 (1981): 24-28.

L'Ecuyer, Catherine. "La perspective montessorienne face au mouvement de l'éducation nouvelle dans la francophonie européenne du début du XXe siècle." European Review of History: Revue Européenne d'histoire 27, no 5 (2020): 651-682.

Lemercier, Claire. "Formal network methods in history: why and how?" En Social Networks, Political Institutions, and Rural Societies, ed. Georg Fertig, 281-310. Turnhout: Brepols Publishers, 2015.

Luzuriaga, Lorenzo. Historia de la Educación y de la Pedagogía. Buenos Aires: Losada, $1965^{6}$.

Llorca, Ángel. Desde la escuela y para la escuela. Escritos pedagógicos y diarios escolares, ed. María del Mar del Pozo Andrés. Madrid: Biblioteca Nueva, 2008.

McCulloch, Gary y Roy Lowe, eds., "Centre and periphery - networks, space and geography in the history of education." History of Education 32, no. 5 (2003): 457-594.

Middleton, Sue C. "Clare Soper's hat: New Education Fellowship correspondence between Bloomsbury and New Zealand (1938-1946)." History of Education 43, no. 1 (2013): 92-114.

Middleton, Sue C. "New Zealand Theosophists in "New Education" networks, 1880s1938." History of Education Review 46, no. 1 (2017): 42-57. 
Penalva Mora, Vicente. "El orientalismo en la cultura española en el primer tercio del s. XX. La Sociedad Teosófica Española (1888-1940)". Tesis doctoral, Universidad Autónoma de Barcelona, 2013.

Pozo Andrés, María del Mar del. "Madrid, febrero de 1927: In Memoriam de Pestalozzi. Las cinco conmemoraciones de un centenario polémico." En La recepción de la pedagogía pestalozziana en las sociedades latinas, ed. Julio Ruiz Berrio al., 453472. Madrid: Endymion, 1998.

Pozo Andrés, María del Mar del. "La Escuela Nueva en España: Crónica y semblanza de un mito." Historia de la Educación. Revista Interuniversitaria 22-23 (2003-2004): 317-346.

Pozo Andrés, María del Mar del. "La renovación pedagógica en España (1900-1939): Etapas, características y movimientos." En V ${ }^{\circ}$ Encontro lbérico de História da Educação. Renovação Pedagógica, ed. Ernesto Candeias, 115-159. Castelo Blanco: Alma Azul, 2005.

Pozo Andrés, María del Mar del. "Las 'fundaciones' de Ángel Llorca." En Comunidades Familiares de Educación. Un modelo de renovación pedagógica en la Guerra Civil, 15-151. Barcelona: 0ctaedro, 2008.

Pozo Andrés, María del Mar del. Justa Freire o la pasión de educar. Biografía de una maestra atrapada en la historia de España (1896-1965). Barcelona: Octaedro, 2013.

Pozo Andrés, María del Mar del y Sjaak Braster. "The power of networks in the marketing of pedagogical ideals: the Dalton Plan in Great Britain (1920-1925)." History of Education 47, no. 6 (2018): 840-864.

Rabelo, Rafaela y Diana Vidal. "A seção brasileira da New Education Fellowship: (des) encontros e (des)conexões." En Movimento internacional da educação nova, eds. Diana Gonçalves Vidal y Rafaela Silva Rabelo, 25-47. Belo Horizonte: Fino Traço editores, 2020.

Rawson, W. ed. New Education Fellowship. Sixth World Conference. Nice. MCMXXXII. Full Report. London: New Education Fellowship, s.a.

Rawson, W. ed., A New World in the Making. An International Survey of the New Education. London: New Education Fellowship, 1933.

Retter, Hein. Protestantismus und Reformpädagogik im Úbergang zur Demokratie. Studien zur Pädagogik Peter Petersens. Frankfurt: Peter Lang, 2007. 
Sinha, Rabinda. "A Critical History and Evaluation of the NEF from its Foundation in 1920". MA: Universidad de Sheffield, 1971.

Solà de Sellarès, María. Irradiación de una biografía: María Solà de Sellarès. México: Costa-Amic Editores, 1987.

Soler i Mata, Joan. "Entre Europa i Amèrica Llatina: Adolphe Ferrière i l'Escola Nova a Barcelona." Temps d'Educació 35 (2008): 229-248.

Soler i Mata, Joan. "María Solà de Sellarès: Teosofía, Educació i Escola Nova a Catalunya." Annals del Patronat d'Estudis Històrics d'Olot i Comarca 21 (2010): 165-182.

Soler i Mata, Joan. "The Rousseau Institute of Geneva's influence on and presence in catalan pedagogy in the first third of the $20^{\text {th }}$ century." Catalan Social Sciences Review 1 (2012): 58-87.

Soler, Joan. "Théosophie et éducation en Espagne (1891-1939): espaces de sociabilité et réseaux éducatifs." En Éduquer dans et hors l'école. Lieux et milieux de formation. XVII - XXe siècle, eds. Bruno Garnier y Pierre Kahn, 87-104. Rennes: Presses Universitaires de Rennes, 2016.

Sureda García, Bernat y Sara González Gómez. "Discurso pedagógico y defensa del magisterio en Rufino Carpena Montesinos." História da Educação 21, no. 51 (2017): 229-251.

Van Gorp, Angelo, Marc Depaepe y Frank Simon. "Backing the actor as agent in discipline formation: an example of the "secondary disciplinarization" of the educational sciences, based on the networks of Ovide Decroly (1901-1931)." Paedagogica Historica 40, nos. 5-6 (2004): 591-616.

Van Gorp, Angelo, Frank Simon y Marc Depaepe. "Frictions and fractions in the new education fellowship, 1920s-1930s: Montessori(ans) vs. Decroly(ans)." History of Education \& Children's Literature XI, no. 1 (2017): 251-270.

Wagnon, Sylvain. "La correspondance d'Ovide Decroly (1871-1932): reflet d'une "internationale" de la psychologie européenne dans la première moitié du XXe siècle?." Recherches \& Éducations 9 (2013): 131-151.

Wagnon, Sylvain. "Les théosophes et l'organisation internationale de l'éducation nouvelle (1911-1921)." REHMLAC+ 9, no. 1 (2017): 146-180.

Watanabe, Yuko. "Internationalization in the New Education Fellowship Japan Section: 'Solidarité' and Kyunojo Uenuma." The Japanese Journal of Educational Research 80, no, 2 (2013): 235-246. 
Watras, Joseph. "The New Education Fellowship and UNESCO's programme of fundamental education." Paedagogica Historica 47, no. 1-2 (2011): 191-205.

White, Margaret $\mathrm{H}$. "The New Education Fellowship: An international community of practice." New Era in Education 82, no. 3 (2001): 71-75.

\section{Archivos}

Records of the World Education Fellowship (1920-1995), Archivos del Instituto de Educación. Londres.

Correspondencia de Decroly con educadores españoles, Centre d'Études Decrolyennes, Uccle (Bruselas).

"Viejos Papeles” de Ángel Llorca y Legado Justa Freire. Fundación Ángel Llorca.

Resumen del Petit Journal de Ferrière realizada por V. Czaka, R. Gerber y A. Reymond y texto original del viaje a Madrid y Barcelona (diciembre de 1930), Archivos en línea de la Universidad de Ginebra, Instituto J.J. Rousseau.

Documentos y fotografías de Rodolfo Tomás y Samper, donados por su viuda, Elena Álvarez, Archivo de María del Mar del Pozo Andrés. 